GISELE BRAGA PINHEIRO

\title{
CONTRIBUIÇÃO SENSORIAL NA FACILITAÇÃO DO ESTÍMULO PRECEDENTE
}

Tese apresentada ao Programa de PósGraduação em Fisiologia e Biofísica do Instituto de Ciências Biomédicas da Universidade de São Paulo, para obtenção do Título de Doutor em Ciências.

São Paulo 
GISELE BRAGA PINHEIRO

\section{CONTRIBUIÇÃO SENSORIAL NA FACILITAÇÃO DO ESTÍMULO PRECEDENTE}

Tese apresentada ao Programa de Pós-Graduação em Fisiologia e Biofísica do Instituto de Ciências Biomédicas da Universidade de São Paulo, para obtenção do Título de Doutor em Ciências.

Área de Concentração: Fisiologia Humana.

Orientador: Prof. Dr. Luiz Eduardo Ribeiro do Valle.

São Paulo

2010 
DADOS DE CATALOGAÇÃO NA PUBLICAÇÃO (CIP)

Serviço de Biblioteca e Informação Biomédica do

Instituto de Ciências Biomédicas da Universidade de São Paulo

reprodução não autorizada pelo autor

Pinheiro, Gisele.

Contribuição sensorial na facilitação do estímulo precedente I Gisele Pinheiro. -- São Paulo, 2010.

Orientador: Luiz Eduardo Ribeiro do Valle.

Tese (Doutorado) - Universidade de São Paulo. Instituto de Ciências Biomédicas. Departamento de Fisiologia e Biofísica. Área de concentração: Fisiologia Humana. Linha de pesquisa: Atenção temporal.

Versão do título para o inglês: Sensory contribution to the facilitation of the warning stimulus.

Descritores: 1. Percepção visual $\quad$ 2. Atenção $\quad 3$. Tempo de reação 4. Detecção de sinal (percepção) I. Ribeiro do Valle, Luiz Eduardo II. Universidade de São Paulo. Instituto de Ciências Biomédicas. Programa de Pós-Graduação em Fisiologia e Biofísica III. Título. 
A Comissão Julgadora dos trabalhos de Defesa da Tese de Doutorado, em sessão pública realizada a .$/$. considerou

\section{( ) Aprovado(a) ( ) Reprovado(a)}

\begin{tabular}{|c|c|}
\hline Examinador(a): & Assinatura: .............. \\
\hline & Nome: .............. \\
\hline & Instituição: . \\
\hline Examinador(a): & Assinatura: \\
\hline & Nome: .............. \\
\hline & Instituição: ........ \\
\hline Examinador(a): & Assinatura: \\
\hline & Nome: .......... \\
\hline & Instituição: ......... \\
\hline Examinador(a): & Assinatura: . \\
\hline & Nome: .............. \\
\hline & Instituição: ........ \\
\hline Presidente: & Assinatura: . \\
\hline & Nome: ..................... \\
\hline
\end{tabular}




\section{AGRADECIMENTOS}

Ao professor Luiz Eduardo Ribeiro do Valle por ser exemplo de mestre e orientador. Aos professores Marcus Vinícius C. Baldo, Peter Claessens e Luiz Renato Rodrigues Carreiro pelas importantes contribuições no exame de qualificação.

Aos colegas de laboratório que fizeram parte da minha trajetória, em diferentes momentos ao longo do Mestrado e Doutorado: Aline, Beatriz, Camila, Débora, Fernanda, Guadalupe, Klebert, Luana, Maria Clara, Miriam, Sara, Telma,Vivian e Viviane. Em especial agradeço à Giuliana, Mariana e Thais pelo apoio, acolhida, parceria e muitos momentos de alegria.

Ao José Maria, secretário da pós-graduação, por ser modelo de competência e dedicação e aos voluntários participantes da pesquisa.

Aos meus diretores, Prof. Carlos Alexandre MiglinsKi, Prof. Carlos Alberto Ramos Pinto e Vitório Buongiorno, pela compreensão necessária para a realização deste estudo.

Aos meus pais, Marco e Leila, e aos meus irmãos, Daniele (in memoriam), Leandro e Leonardo, por serem referência de amor, força e superação.

Ao Renato, meu grande companheiro, por todo amor, alegria, compreensão e apoio para a conclusão deste estudo.

Aos meus queridos amigos e familiares (avós, tios e primos) que acompanharam as conquistas e dificuldades encontradas no caminho até a chegada deste momento. Em especial agradeço à tia Regina, por seu exemplo, carinho e apoio constante. 
Porque o único sentido oculto das coisas

É elas não terem sentido oculto nenhum

É mais estranho do que todas as estranhezas

E de que os sonhos de todos os poetas

E os pensamentos de todos os filósofos,

Que as coisas sejam realmente o que parecem ser E não haja nada que compreender.

(Fernando Pessoa) 


\section{RESUMO}

PINHEIRO, G. B. Contribuição sensorial na facilitação do estímulo precedente. 2010. 70 f. Tese (Doutorado em Ciências) - Instituto de Ciências Biomédicas, Universidade de São Paulo, São Paulo, 2010.

A ocorrência de um estímulo auditivo imediatamente antes de um estímulo alvo visual reduz o tempo de reação em dezenas de milisegundos, um efeito atribuído a atenção temporal automática. O presente estudo investigou se este efeito é resultante de uma facilitação de mecanismos sensoriais. Dois experimentos foram realizados. No primeiro, foi realizada uma tarefa de tempo de reação simples por meio da resposta a estímulos alvos visuais com variações em sua detectabilidade. Esperava-se que o tamanho do efeito facilitador pudesse aumentar com o aumento da dificuldade de detecção do alvo. No segundo experimento foi realizada uma tarefa de acurácia. Os dados foram analisados pela teoria de detecção de sinal. Esperava-se que o estímulo precedente possibilitasse o aumento da detectabilidade do alvo e redução do critério de resposta. No primeiro experimento, não houve influência do estímulo precedente no aumento da detectabilidade do alvo. Os resultados do segundo experimento indicaram haver influência do estímulo precedente no aumento da detectabilidade do alvo e redução do critério pra a resposta. Esses resultados reforçam a teoria de que a atenção temporal automática facilita o processamento sensorial.

Palavras-chave: Atenção temporal. Tempo de reação. Acurácia. Detecção. Estímulo precedente. 


\begin{abstract}
PINHEIRO, G. B. Facilitation by automatic temporal expectation. 2010. 70 f. Ph. D. Thesis (Physiology and Biophysics) - Instituto de Ciências Biomédicas, Universidade de São Paulo, São Paulo 2010.
\end{abstract}

The occurrence of an auditory stimulus immediately before a visual target stimulus shortens reaction time by tens of milliseconds, an effect attributed to automatic temporal expectation. The present study investigated whether this effect results from a facilitation of sensory mechanisms. Two experiments were performed. In the first one the volunteers performed a simple reaction time task. They responded to visual targets which differ in detectability. It was expected that the size of the facilitatory effect would increase with the difficulty of target detection. In the second experiment the volunteers performed an accuracy task. Its data were analyzed on basis of signal detection theory. It was expected that the warning stimulus would increase the detectability of the target and lower the criterion to respond. The results of the first experiment did not indicate any influence of target detectability. The results of the second experiment indicate that both the detectability of the target and the criterion to respond were affected by the warning stimulus. These results provide support to the idea that automatic temporal expectancy facilitates sensory processing.

Key-words: Automatic temporal expectation. Temporal attention. Reaction time. Accuracy. Detection. Warning stimulus,. 


\section{LISTA DE ILUSTRAÇÕES}

Figura 1: Esquema representativo do método de fatores aditivos sobre 0 processamento da via estímulo-resposta.

Figura 2: Representação gráfica do método de fatores aditivos. A) Condição em que não ocorre interação do estímulo precedente e a dificuldade sensorial ou motora; B) Condição em que ocorre interação do estímulo precedente e a dificuldade.

Figura 3: Representação esquemática da ativação de uma população neuronal por um estímulo sensorial intenso $(A)$ e fraco $(B)$ na ausência (quadros à esquerda) e na presença (quadros à direita) de uma estimulação precedente auditiva.

22

Figura 4: Representação esquemática da interação sensorial do estímulo precedente auditivo e a intensidade do alvo sobre o "estágio A" da via estímulo-resposta. 23

Figura 5: Representação esquemática da interação motora entre o estímulo precedente auditivo e o número de submovimentos sobre o "estágio C" da via de processamento estímulo-resposta. 25

Figura 6: Disposição esquemática dos materiais utilizados na realização dos experimentos. 31

Figura 7: Representação esquemática da apresentação dos estímulos na primeira e na segunda sessão. O E2 foi apresentado à direita ou à esquerda do ponto de fixação,

em tentativas diferentes. .33 
Figura 8: Representação esquemática do padrão temporal da estimulação auditiva (E1) e visual (E2) 33

Figura 9: Tempo de reação (média \pm e.p.m.) em milisegundos, das mãos esquerda e direita, nas condições sem som e com som para as dificuldades 1 (20,0 cd/m2), 2 (10,0 cd/m2), $3(5,0 \mathrm{~cd} / \mathrm{m} 2)$ e $4(2,5 \mathrm{~cd} / \mathrm{m} 2)$ de detecção do estímulo alvo. 37

Figura 10: Tempo de reação (média \pm e.p.m.) em milisegundos, sem distinção de mão, nas condições sem som e com som para as dificuldades 1 (20,0 $\mathrm{cd} / \mathrm{m} 2), 2(10,0 \mathrm{~cd} / \mathrm{m} 2), 3(5,0 \mathrm{~cd} / \mathrm{m} 2)$ e $4(2,5 \mathrm{~cd} / \mathrm{m} 2)$ de detecção do estímulo alvo. 38

Figura 11: Tempo de reação (média \pm e.p.m.) em milisegundos, na condição compatível e incompatível, nas condições sem som e com som, para as dificuldades $1(20,0 \mathrm{~cd} / \mathrm{m} 2), 2(10,0 \mathrm{~cd} / \mathrm{m} 2), 3(5,0 \mathrm{~cd} / \mathrm{m} 2)$ e $4(2,5 \mathrm{~cd} / \mathrm{m} 2)$ de detecção do estímulo alvo.

Figura 12: Representação esquemática da apresentação dos estímulos na primeira e na segunda etapa. O E2 (estímulo alvo visual) era apresentado no centro da tela, em torno do ponto de fixação. O E1 (estímulo precedente auditivo) somente era apresentado na segunda etapa. 45

Figura 13: Representação do valor da detectabilidade na condição sem som e com som, para cada participante.

Figura 14: Representação da média da detectabilidade dos participantes na condição sem som e com som, com erro padrão da média. 48

Figura 15: Representação do valor do critério na condição sem som e com som, para cada participante.

Figura 16: Representação da média do critério dos participantes na condição sem som e com som, com erro padrão da média. 
Figura 17: Representação de um exemplo de tarefa "sim-não" para reconhecimento de face. a) Os participantes respondiam "sim" para as faces em que julgavam terem visto anteriormente e diziam "não" para àquelas que julgavam não terem visto anteriormente. As curvas S1 e S2 representam, respectivamente, o reconhecimento de faces novas e faces antigas e delimitam o critério. b) A distância entre os picos das duas curvas representa a detectabilidade. . 


\section{LISTA DE TABELAS}

Tabela 1 - Média dos tempos de reação ( média \pm e.p.m.) em milisegundos das mãos esquerda e direita, nas condições sem som (SS) e com som (CS), para as diferentes luminâncias do estímulo alvo $(20,0,10,0,5,0$ e 2,5 $\mathrm{cd} / \mathrm{m} 2)$.

Tabela 2 - Resultados da análise de variância tendo como fatores a luminância do estímulo alvo (20,0,10,0,5,0 e 2,5 cd/m2 ), o estímulo precedente-E1 (ausente ou presente) e a mão (esquerda ou direita). Os resultados significantes estão indicados com um asterisco $\left(^{*}\right)$. (Gl $=$ graus de liberdade; $F$ = razão entre $o$ quadrado da média do efeito e o do erro; $p=$ nível de significância).

Tabela 3 - Média dos tempos de reação (média \pm e.p.m.) em milisegundos para as condições entre estímulo alvo e mão de resposta compatível e incompatível, nas condições sem som e com som, para as diferentes luminâncias do estímulo alvo.

Tabela 4 - Resultados da análise de variância tendo como fatores a compatibilidade entre estímulo alvo e mão de resposta (compatível ou incompatível), luminância do estímulo alvo $(20,0,10,0,5,0$ e 2,5 cd/m2 ) e o estímulo precedente-E1 (ausente ou presente). Os resultados significantes estão indicados com um asterisco $\left(^{*}\right)$. $(\mathrm{Gl}=$ graus de liberdade; $\mathrm{F}=$ razão entre o quadrado da média do efeito e o do erro; $p$ = nível de significância)....39

Tabela 5 - Distribuição das tentativas por cada uma das quatro condições possíveis, de acordo com a presença ou ausência do estímulo precedente auditivo (E1) e com a presença ou ausência do estímulo alvo visual (E2). 
Tabela 6 - Valores de detectabilidade e critério para cada voluntário, nas condições

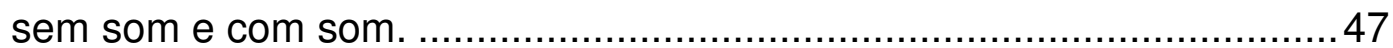




\section{SUMÁRIO}

1 INTRODUÇÃO ............................................................................................14

1.1 Efeito facilitador do estímulo precedente .......................................... 15

1.2 Atenção temporal e Preparação temporal ......................................16

1.3 Mecanismos neurais do efeito faciltador do estímulo precedente ..........18

1.4 Envolvimento de mecanismos sensoriais no efeito facilitador do estímulo

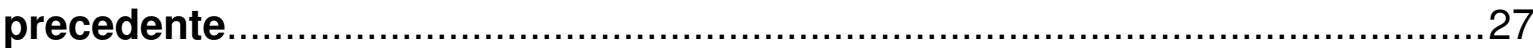

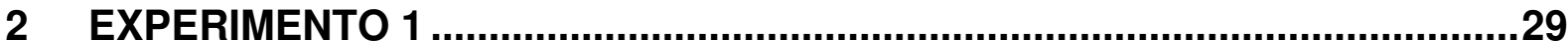

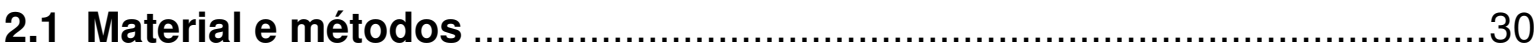

2.1.1 Participantes ................................................................................ 30

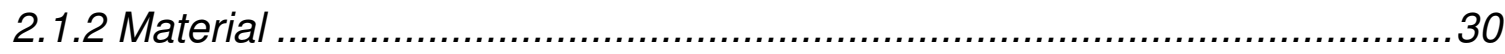

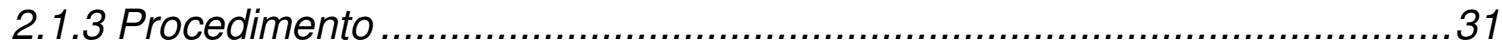

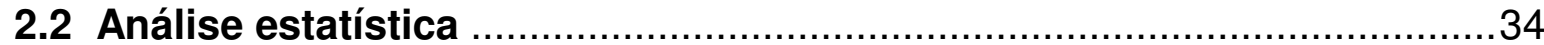

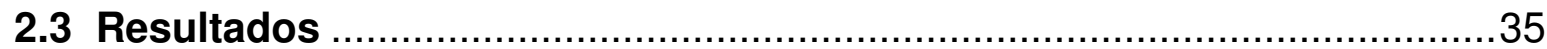

2.3.1 Tempo de reação ........................................................................... 35

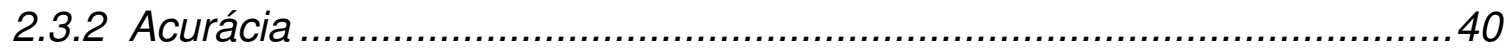

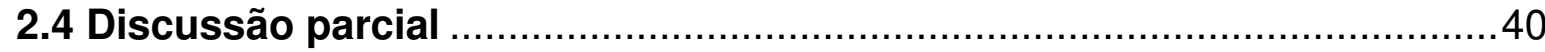

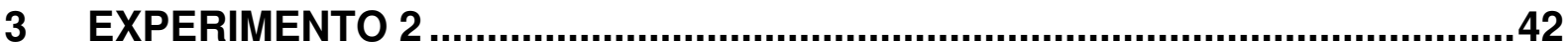

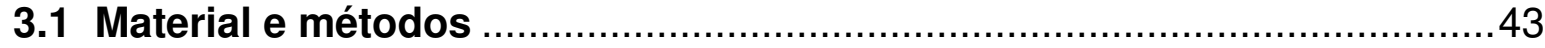

3.1.1 Participantes .......................................................................... 43

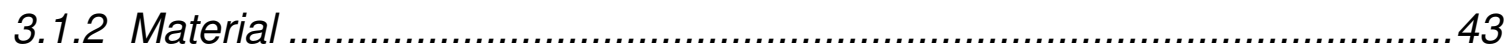

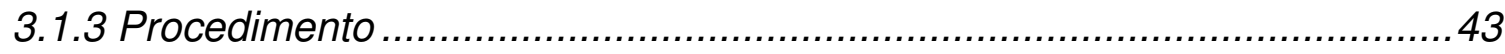

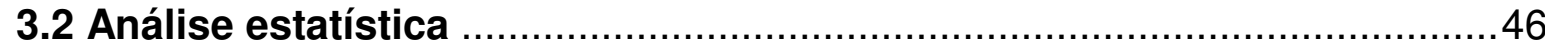

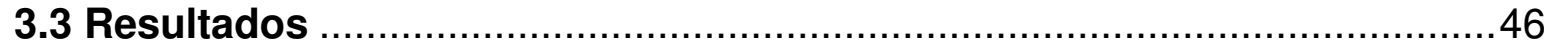


3.3.1 Detecção

3.4 Discussão parcial

4 DISCUSSÃO GERAL

5 CONCLUSÃO

REFERÊNCIAS

ANEXOS

ANEXO A - Teoria de detecção de sinal. 62

ANEXO B - Questionário de Edinburgh............................................................67

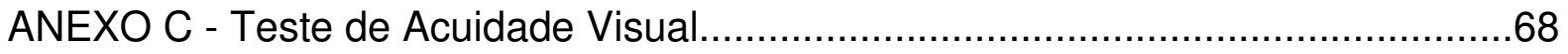

ANEXO D - Termo de Consentimento Livre e Esclarecido ......................................69

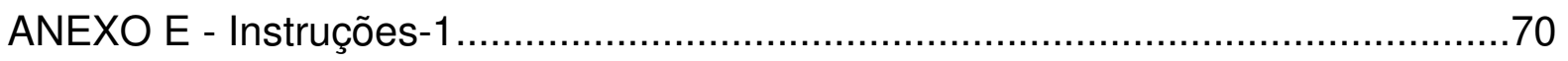

ANEXO F - Teste de Ishihara para daltonismo....................................................

ANEXO G - Dados utilizados para análise estatística do Experimento 1...................72

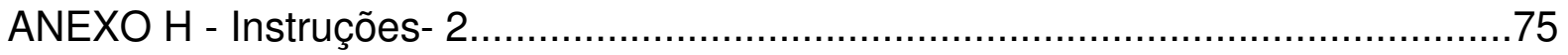

ANEXO I - PEST (Parameter Estimation by Sequential Testing) .......................76

ANEXO J - Dados utilizados para análise estatística do Experimento 2...................78

ANEXO L - Versão preliminar do manuscrito para publicação. 


\section{INTRODUÇÃO}

Final de um grand slam de uma partida de tênis. Cada ponto é fundamental. Os adversários estão com a atenção focada um no outro. Saques e rebatidas são a essência para o resultado positivo e, portanto, servem como referências espaciais e temporais. Ao fazer uma descrição da tarefa desempenhada em uma partida de tênis, pode ser considerado que a ação esperada na tarefa é a batida na bola com a raquete de tênis o mais rápido e assertivamente possível. Tomando como referência uma partida de tênis com dois jogadores, representados como Jogador A e Jogador $B$, o estímulo alvo para desencadear a resposta desta tarefa seria o momento em que o Jogador A (adversário) bate com sua raquete na bola. 0 momento em que o corpo do adversário se movimenta, previamente ao momento de sua batida na bola, pode ser caracterizado como estímulo temporal que facilite a reação do Jogador B (futuro rebatedor), como indicador da velocidade da bola, por exemplo. Quando o Jogador A está na extrema direita da quadra (visão do Jogador B) com o corpo posicionado lateralmente, e a quadra encontra-se à sua esquerda, o movimento do seu braço e a posição do seu corpo sugerem que a bola será rebatida para a esquerda do campo do Jogador B. Essa posição assumida pelo Jogador A, anterior à batida, já pode gerar uma ação antecipatória que fará com que o Jogador $B$ reaja mais rapidamente ao estímulo alvo (batida com a raquete na bola pelo adversário).

Conhecer as bases fisiológicas de situações comportamentais, como a partida de tênis descrita, há muito tempo vem sendo objeto de investigação. O que leva o ser humano a desempenhar uma ação de maneira mais rápida na presença de algum estímulo prévio à tarefa, ainda que este estímulo não esteja relacionado diretamente à tarefa a ser desempenhada, é algo que desperta questionamentos. Por exemplo, de que modo pode ser explicada essa facilitação proporcionada pelo estímulo prévio? Que mecanismos do aspecto sensório-motor poderiam predispor essa facilitação? Seria uma facilitação de processos perceptivos? Seria uma facilitação do planejamento motor ou da execução de uma resposta motora?

Para que esses questionamentos possam ser investigados, faz-se necessário considerar alguns conceitos já definidos na literatura sobre o efeito facilitador do estímulo precedente, o contexto temporal em que ocorre e os diferentes 
posicionamentos existentes acerca dos mecanismos neurais envolvidos neste processo.

\subsection{Efeito facilitador do estímulo precedente}

Pinheiro (2006) já fez referência ao fato de que a ocorrência de um estímulo sensorial (visual, auditivo) precedendo o estímulo alvo visual geralmente reduz o tempo de reação de algumas dezenas de milisegundos (DAVIS e GREEN, 1969; FERNANDEZ-DUQUE e POSNER, 1997; KEUSS, 1972; LANSING et al., 1959) e de que a magnitude deste efeito facilitador depende da modalidade do estímulo precedente, pois estímulos auditivos causam, em geral, efeitos maiores do que estímulos visuais (DAVIS e GREEN, 1969; FERNANDEZ-DUQUE e POSNER, 1997; LETOURNEAU et al., 1986; SANABRIA; LUPIÁÑEZ; SPENCE, 2007). A intensidade do estímulo precedente também seria importante, já que estímulos auditivos intensos produzem efeitos maiores do que estímulos auditivos fracos (KEUSS, 1972; ULRICH e MATTES, 1996; MILLER et al., 1999).

O efeito facilitador do estímulo precedente também está relacionado em certa medida com o intervalo que o separa do estímulo alvo. Lansing et al. (1959) comparou os tempos de reação a um estímulo visual apresentado entre 50 e 1000 ms após um estímulo auditivo. Eles encontraram uma redução progressiva do tempo de reação à medida que o intervalo entre os dois estímulos aumentava. Esta redução já era evidente quando o intervalo entre os estímulos era de $150 \mathrm{~ms}$ e atingia um máximo para um intervalo entre os estímulos de 300 a 400 ms. Usando também um estímulo precedente auditivo e um estímulo alvo visual, Davis e Green (1969) encontraram um efeito facilitador máximo em 200 ms. De acordo com Niemi e Näätänen (1981), o efeito facilitador de um estímulo precedente aumentaria com o intervalo entre os estímulos quando este é menor do que 1000 ms. Para intervalos mais longos (por exemplo, 1000 a 4000 ms) o efeito facilitador decresceria na medida em que a incerteza temporal aumentasse.

Experimentos realizados por Del Fava e Ribeiro-do-Valle (2004) forneceram evidências de que o efeito facilitador de um estímulo precedente não informativo espacialmente se deve a um preparo para responder de uma determinada forma a um determinado estímulo alvo em um determinado momento, e não a um aumento 
inespecífico da responsividade do organismo como sugerido por alguns autores (BERTELSON e TISSEYRE, 1969; KEUSS, 1972). Correa, Lupiáñez e Tudela (2005) também se referem à orientação da atenção temporal como um preparo específico e relacionado à expectativa temporal. Los, Knol e Boers (2001) atribuíram o efeito facilitador a uma preparação temporal, porém o consideraram inespecífico do ponto de vista sensorial e motor.

\subsection{Atenção temporal e Preparação temporal}

A preparação temporal resultaria da orientação da atenção no tempo, que ocorre quando um evento relevante é esperado. Ela otimiza o comportamento. A atenção temporal parece depender de processos elementares da decodificação do tempo, que ocorrem por exemplo no cerebelo, núcleos da base e córtex frontal (COULL e NOBRE, 1998). A atenção temporal também está associada com a expectativa da ocorrência de um evento. Ao alocar a atenção no tempo tende-se a gerar uma expectativa para a ocorrência de um evento futuro. Esta expectativa envolve áreas como o cortéx pré-frontal bilateral, os córtices pré-motores e o córtex parietal inferior esquerdo (COULL et al., 2000).

Werner, Parrish e Holmer (2009) realizaram um estudo investigativo de atenção temporal sobre como a detectabilidade de um som por crianças e adultos pode ser afetada pela incerteza e expectativa temporal. Utilizaram em seus experimentos somente pistas e alvos auditivos, e os resultados foram submetidos a análise da teoria de detecção de sinal. Com o foco sobre os aspectos temporais deste estudo, é interessante relatar os achados de que pistas auditivas aumentaram a eficiência da detecção. Além disso, com as pistas seguidas de intervalos que gerassem expectativa temporal proporcionaram melhor detecção do som do que os intervalos sem expectativa temporal. Ou seja, a incerteza temporal diminuiu a detectabilidade.

Pestilli, Viera e Carrasco (2007) descreveram que atenção e adaptação são ambos os mecanismos que melhoram o desempenho de uma atividade visual. A atenção melhora o desempenho por aumentar a sensibilidade ao contraste e por aumentar as respostas neurais para os estímulos atendidos enquanto diminui as respostas neurais para os estímulos não atendidos. A adaptação melhora o 
desempenho de detecção pelo aumento da sensibilidade ao contraste por diminuir as respostas neurais para os estímulos que não se modificam. Eles investigaram se, e como, a adaptação e o efeito atencional interagem na sensibilidade ao contraste. Constataram que a atenção aumenta a saliência do estímulo, enquanto a adaptação reduz a saliência do estímulo, de modo que a adaptação não modula a magnitude do efeito atencional. A atenção pode sobrepor a adaptação e restaurar a sensibilidade ao contraste.

Dados obtidos com potenciais evocados sugerem que estágios do processamento perceptual contribuem para os benefícios aos estímulos influenciados pela atenção temporal. A existência de efeitos entre modalidades cruzadas (cross-modais) ressalta a importância do tempo como promovedor de melhorias no desempenho em diferentes modalidades (ALAIS; MORRONE e BURR, 2006; LANGE e RODER, 2006). Na análise de modalidades cruzadas, a entrada de sinais auditivos afetam o processamento de sinais visuais nas etapas precoces do processamento sensório-motor ao invés de nas suas etapas tardias. (BAIER; KLEINSCHIMIDT; MÜLLER, 2006; CIARAMITARO, et al., 2007; ROBINSON e SLOUTSKY, 2007).

Nobre, Correa e Coull (2007) descrevem que a certeza temporal pela ocorrência de um evento pode modular limiares perceptivos para luminâncias, e pode aumentar a discriminabilidade perceptiva de um estímulo visual, bem como pode proporcionar facilitalções no comportamento motor.

$\mathrm{Na}$ possibilidade de haver uma ênfase atencional maior no processamento sensorial ou no processamento motor na dependência das exigências das tarefas sendo realizadas, Henderson e Dittrich (1998) discutiram a importância relativa de uma facilitação do processamento sensorial e de uma facilitação do processamento motor para a ocorrência do efeito facilitador do estímulo precedente. Tarefas mais difíceis do ponto de vista sensorial mobilizariam mais recursos atencionais para o processamento sensorial, enquanto que tarefas mais difíceis no aspecto motor mobilizariam mais recursos atencionais para o processo motor. 


\subsection{Mecanismos neurais do efeito faciltador do estímulo precedente}

Com base nas idéias de Henderson e Dittrich (1998), Pinheiro (2006) investigou a influência do estímulo precedente no processamento sensorial em tarefas em que a dificuldade de detecção do estímulo alvo variava, e no processamento motor em tarefas em que havia a variação da dificuldade de execução da resposta.

O trabalho de Pinheiro (2006) teve como propósito reavaliar a importância relativa de uma facilitação do processamento sensorial e de uma facilitação do processamento motor para a ocorrência do efeito facilitador do estímulo precedente. Mais especificamente, pretendia esclarecer o envolvimento dos mecanismos sensoriais e dos mecanismos motores no efeito facilitador que um estímulo auditivo produz sobre a responsividade a um estímulo alvo visual, com utilização de tarefas de tempo de reação simples e de escolha.

Como a complexidade da resposta é maior em uma tarefa de tempo de reação de escolha, observado pelo aumento do tempo de reação (KLAPP, 1995; MILLER e ANBAR, 1981), era possível que a contribuição dos mecanismos sensoriais e dos mecanismos motores fosse diferente entre as duas tarefas. Em particular, o envolvimento adicional do processo de seleção da resposta na segunda tarefa permitiria verificar se haveria uma influência do estímulo precedente sobre este processo.

Tarefas de tempo de reação simples e de escolha permitem adicionalmente a análise da condição de compatibilidade entre a mão de resposta e o local de aparecimento do estímulo alvo. A disposição espacial relativa do estímulo e da resposta é considerada pelos mecanismos de registro da entrada da informação sensorial (MAGEN e COHEN, 2002) e de seleção da resposta, o que afeta a velocidade e a eficiência do processamento sensório-motor (HOMMEL, 1996).

O efeito da compatibilidade em uma tarefa de TRE, segundo Miller e Anbar (1981), está relacionado com a utilização de um código espacial que associa o estímulo à resposta. A existência de correspondência entre a codificação espacial do estímulo e a codificação espacial da resposta tende a reduzir o tempo de resposta do que quando comparado a ausência da referida correspondência, condição dita incompatível. 
O método de fatores aditivos (MFA), proposto por Sternberg (1969), foi utilizado com a finalidade de determinar a etapa do processamento sensório-motor influenciada pela estimulação precedente. O MFA de Sternberg foi desenvolvido após o método de subtração de Donders. Este pretendia a mensuração da duração dos estágios de processamento entre estímulo e resposta. No entanto, não fornecia garantia de que, com o acréscimo ou retirada de alguns estágios do processamento, outros estágios não fossem alterados. O MFA não permite saber a duração dos estágios de processamento, mas possibilita conhecer a existência dos estágios (quais são eles) e algumas de suas características. Por meio de determinadas mudanças nas condições dos experimentos seria possível influenciar determinados estágios do processamento sensório-motor, pois parte do princípio de que os estágios deste processamento são independentes. Um estágio corresponde a uma série de processos sucessivos que operam, a partir da aferência de um estímulo, na produção de uma resposta. A média da duração de um estágio depende somente da entrada dos estímulos e os níveis dos fatores que o influenciam e não necessariamente da média de duração dos demais estágios.

O esquema apresentado na figura 1 abaixo permite a visualização do possível local de ação de fatores importantes no processamento sensório-motor. $O$ fator consiste em uma influência que, ao variar, causa uma alteração na resposta. Cada fator pode exercer sua influência em um estágio específico do processamento, sem agir em um estágio comum. Quando isso ocorre espera-se que os efeitos dos fatores sejam independentes e aditivos. Porém, quando dois ou mais fatores exercem seus efeitos sobre ao menos um estágio em comum, ou seja, influenciam a mesma etapa do processamento, espera-se que haja uma interação dos seus efeitos. 


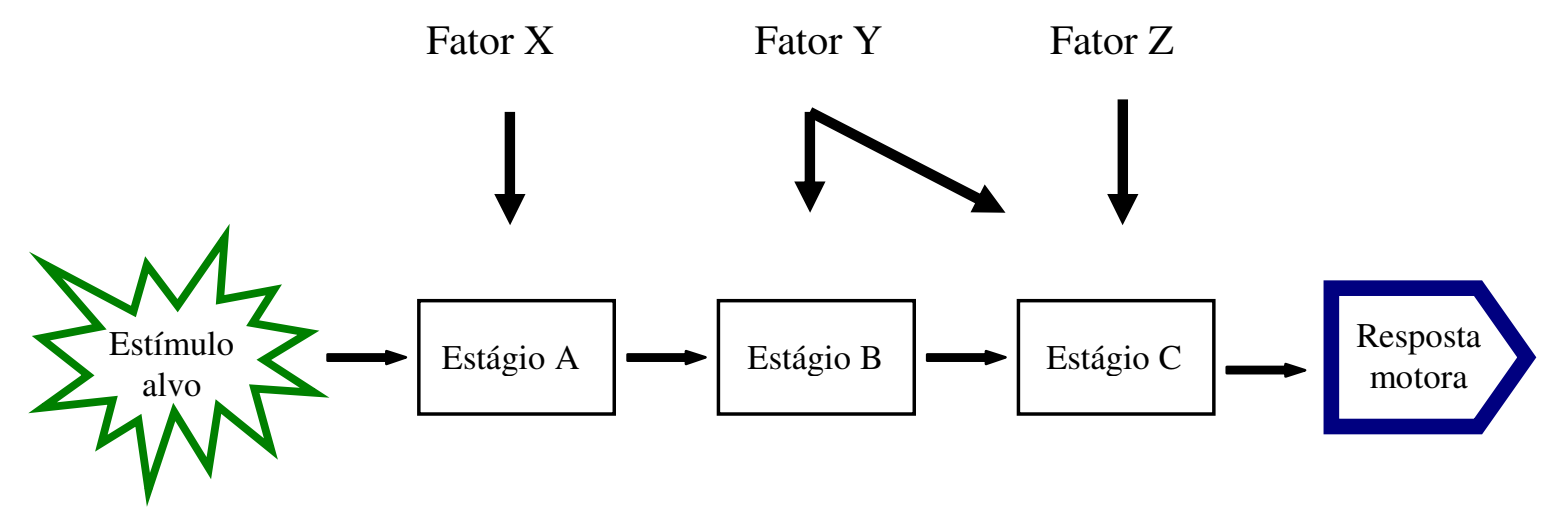

Figura 1: Esquema representativo do método de fatores aditivos sobre o processamento da via estímulo-resposta.

Ao considerar que a presença de um estímulo precedente auditivo reduz 0 tempo de reação ao estímulo visual, pode-se concluir que o estímulo precedente exerce influência em um ou mais estágios do processamento visuo-motor. Se for adicionado um outro fator que modifica o processamento como, por exemplo, a variação da dificuldade do estímulo ou da dificuldade da resposta, e houver uma interação de efeitos, isso possibilitaria o conhecimento sobre qual estágio o som atua.

Esperava-se que quanto maior fosse a dificuldade sensorial ou motora, maior seria o tempo de reação, tanto para a condição em que há a presença do estímulo precedente auditivo quanto na sua ausência. Em uma representação gráfica, uma ascensão paralela do tempo de reação, para as condições sem som e com som, em função da dificuldade indicaria que apesar do estímulo precedente reduzir o tempo de reação, ele beneficiaria as diferentes dificuldades sensórias ou motoras igualmente (Figura $3 \mathrm{~A}$ ). Uma ascensão divergente do tempo de reação, para as condições sem e com som, em função da dificuldade indicaria que o estímulo precedente beneficiaria mais as dificuldades sensórias e motoras maiores (Figura 3 B). Sendo assim, a condição em que fosse encontrada tal interação indicaria qual o mecanismo responsável por esse efeito, se sensorial ou motor. 


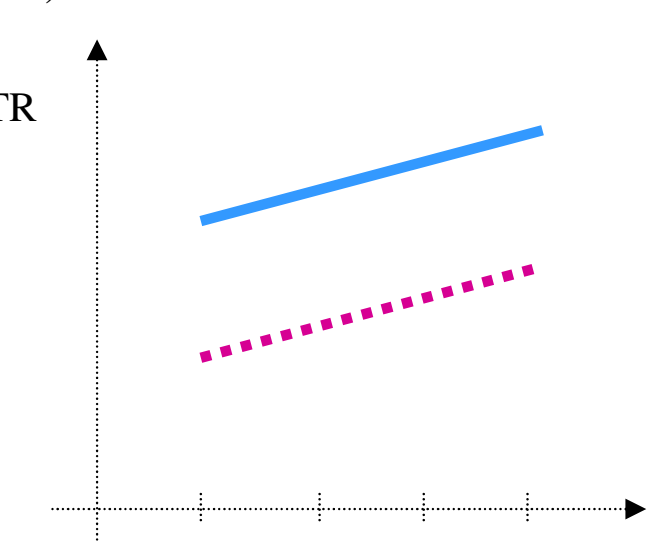

Dificuldade
B)

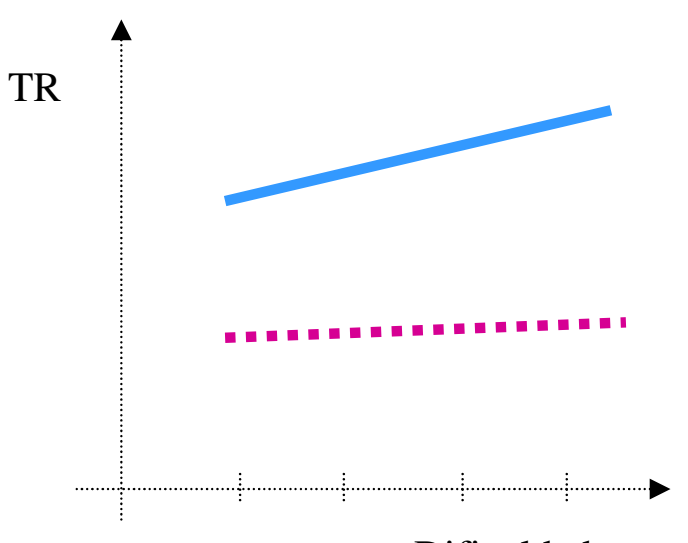

Dificuldade

Figura 2: Representação gráfica do método de fatores aditivos. A) Condição em que não ocorre interação do estímulo precedente e a dificuldade sensorial ou motora; B) Condição em que ocorre interação do estímulo precedente e a dificuldade.

A figura 3 tem como propósito auxiliar na compreensão da razão da influência facilitadora do som ser maior para estímulos alvos mais difíceis de serem detectados ou respostas motoras mais difíceis de serem executadas. Cada quadro representa uma população neuronal e cada disco corresponde a um neurônio. Um estímulo alvo intenso (A) produz a ativação de uma população neuronal grande (discos vermelhos). Um estímulo alvo de baixa intensidade (B) produz a ativação de uma população neuronal pequena (discos vermelhos). Os neurônios vizinhos aos neurônios ativos ficam apenas facilitados (discos cinzas), ou seja, com seu potencial de membrana próximo ao limiar de deflagração do potencial de ação. A apresentação prévia do som possibilita que esses neurônios que seriam apenas facilitados pelo estímulo alvo tornem-se ativos (discos amarelos), o que no fim resulta em uma resposta neuronal maior. O número de neurônios adicionais passíveis de serem mobilizados por um estímulo alvo fraco é maior do que aquele por um estímulo intenso. Dessa forma, o processamento de um estímulo alvo de baixa intensidade obteria maior benefício do som do que o processamento de um estímulo alvo de grande intensidade. Raciocínio semelhante pode ser feito para respostas motoras mais simples e mais difíceis. 


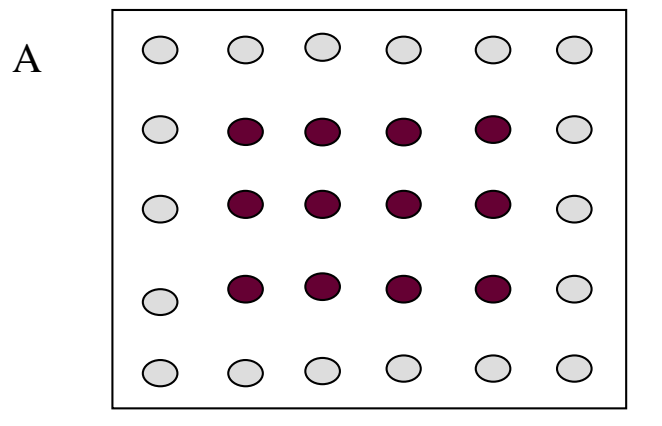

Sem som

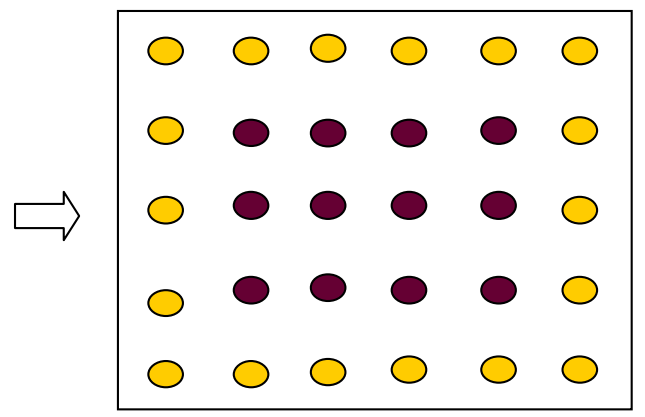

Com som

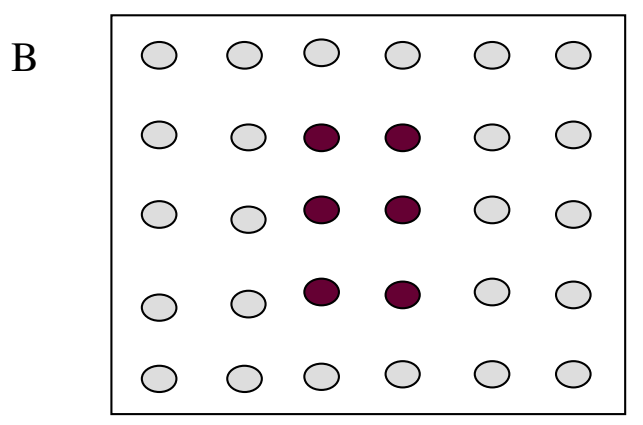

Sem som

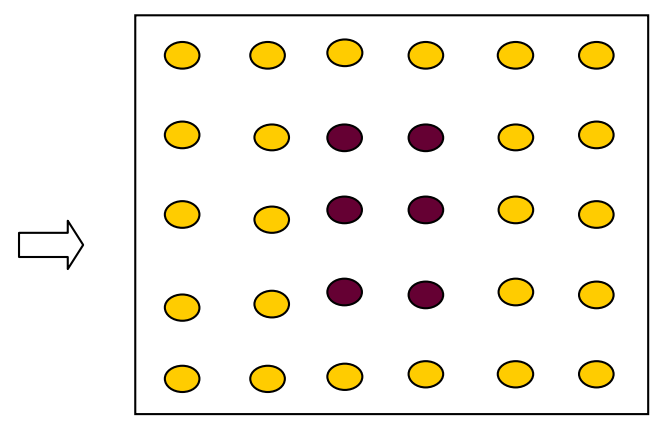

Com som

Figura 3: Representação esquemática da ativação de uma população neuronal por um estímulo sensorial intenso $(A)$ e fraco $(B)$ na ausência (quadros à esquerda) e na presença (quadros à direita) de uma estimulação precedente auditiva.

A possível influência sobre o processamento sensorial foi testada no estudo de Pinheiro (2006) com a utilização de quatro intensidades (quatro luminâncias) diferentes de estímulos alvos apresentados. Mudança na característica de um estímulo como, por exemplo, na sua intensidade geralmente altera o desempenho em estudos psicofísicos (MAUK e BUONOMANO, 2004). O estímulo precedente auditivo ocorreu aleatoriamente em metade das tentativas, com cada intensidade. Um grupo de voluntários realizou esta situação experimental em uma tarefa de tempo de reação simples e um outro em uma tarefa de tempo de reação de escolha. Caso o efeito facilitador dependesse de modo importante de uma facilitação do processamento sensorial, deveria aparecer uma interação dos dois fatores 
considerados (intensidade do alvo e estimulação precedente) (STERNBERG, 1969). A figura 4 representa esquematicamente essa situação.

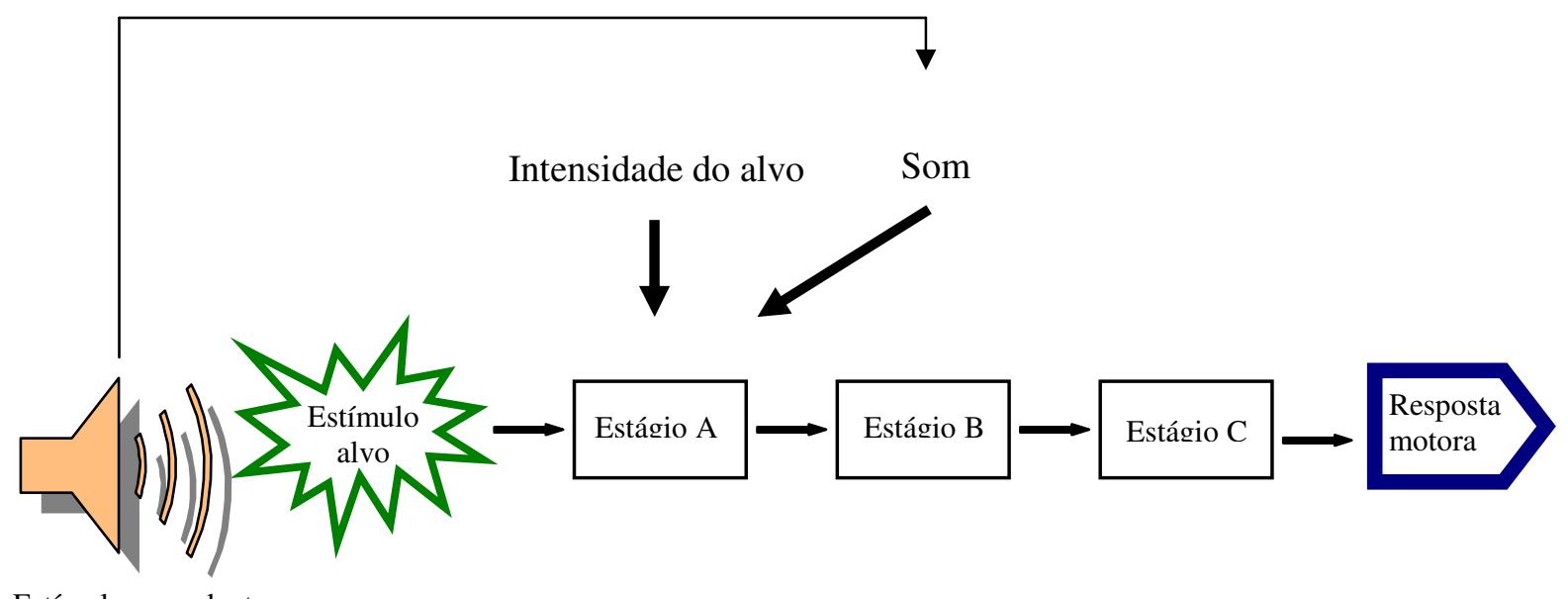

Estímulo precedente

Figura 4: Representação esquemática da interação sensorial do estímulo precedente auditivo e a intensidade do alvo sobre o "estágio A" da via estímulo-resposta.

Os resultados encontrados foram o aumento do tempo de reação diante do aumento da dificuldade para detecção do alvo. Um efeito facilitador do estímulo precedente foi evidenciado no tempo de reação. No entanto, este efeito não diferiu significantemente entre as quatro intensidades testadas. Estes resultados, em princípio, contrariam a hipótese de que a facilitação promovida pelo estímulo precedente resulta de um aumento da eficiência do processamento sensorial. Por outro lado, o efeito facilitador tendeu a aumentar na intensidade mais baixa do estímulo alvo.

Verificou-se que na ausência do som o tempo de reação para as condições incompatíveis foi maior do que para as compatíveis. Em geral, quando a dimensão espacial ou simbólica de um estímulo coincide com a resposta, pode ocorrer seleção rápida e direta. Acredita-se que cada par de estímulo-resposta compatível é processado automaticamente. Basta um comando de "vai", fornecido pelo estímulo para que ocorra a execução motora. Quando existe conflito entre as dimensões, como na condição incompatível, o estímulo tende a iniciar a resposta que contém as mesmas dimensões que as suas, porém está resposta é incorreta. A necessidade de inibir a resposta incorreta, selecionar e programar a resposta correta implicaria em 
mais tempo para sua execução (MILLER e ANBAR, 1981; STOFFELS, 1996). Na presença do estímulo precedente auditivo não houve diferença entre os tempos de reação para a condição compatível e para a incompatível. Considerando que a diferença entre as condições compatível e incompatível foi encontrada na ausência do estímulo precedente auditivo, os dados são sugestivos de que houve influência do som neste processo.

A presença do som parece ter proporcionado uma preparação ótima dos circuitos neurais sensório-motores de modo a beneficiar mais a condição incompatível do que a compatível. Além disso, o efeito facilitador do som aumentou com a diminuição da intensidade do estímulo alvo, tanto para a condição compatível quanto para a incompatível. Estes resultados conferem suporte à idéia de que o estímulo precedente exerce sua influência na mesma etapa do processamento que a intensidade do estímulo alvo, ou seja, na etapa sensorial.

A possível influência sobre o processamento motor foi testada pela emissão de resposta com 1, 2, 3 ou 4 submovimentos. A manipulação da dificuldade da resposta leva à alteração da programação e execução motora (KLAPP, 1995). Também neste caso o estímulo precedente ocorreu aleatoriamente em metade das tentativas em que havia o estímulo alvo, com cada extensão de resposta. Um dos grupos de voluntários realizou esta situação experimental em uma tarefa de tempo de reação simples e o outro em uma tarefa de tempo de reação de escolha. Caso o efeito facilitador dependesse de modo importante de uma facilitação do processamento motor, deveria aparecer uma interação dos dois fatores considerados (extensão da resposta e estimulação precedente) (STERNBERG, 1969). A figura 5 representa esquematicamente esta situação. 


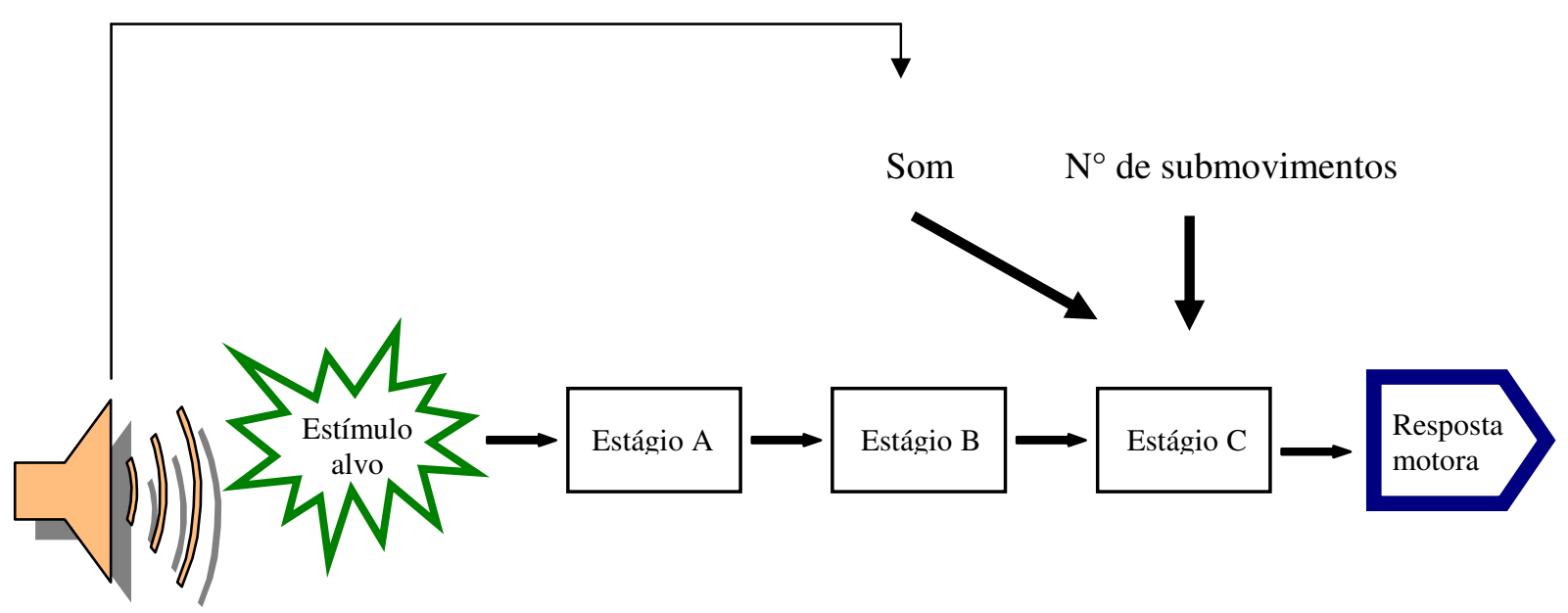

Estímulo precedente

Figura 5: Representação esquemática da interação motora entre o estímulo precedente auditivo e o número de submovimentos sobre o "estágio C" da via de processamento estímulo-resposta.

O resultado da investigação realizada no trabalho anterior para verificar se a influência facilitadora sobre o tempo de reação de um estímulo precedente informativo temporalmente pudesse depender de uma modulação do processamento motor indicou que o tempo de reação aumentou proporcionalmente à dificuldade da resposta (aumento do número de submovimentos) e a presença do estímulo auditivo reduziu o tempo de reação, reafirmando sua influência facilitadora. $O$ efeito facilitador do estímulo precedente, no entanto, não diferiu significativamente entre os quatro níveis de dificuldade da resposta (independente dela ser compatível ou incompatível), o que contraria a hipótese de que a facilitação promovida pelo estímulo precedente pudesse ser devido à maior eficiência do processamento motor.

Os resultados encontrados nesses experimentos demonstram que um estímulo precedente auditivo facilita o tempo de reação a um estímulo alvo visual. Eles são consistentes com os achados anteriores do laboratório (DEL FAVA e RIBEIRO-DO-VALLE, 2004) e com achados de diversos outros estudos (DAVIS e GREEN, 1969; FERNANDEZ-DUQUE e POSNER, 1997; KEUSS, 1972; LANSING et al., 1959) mostrando uma redução do tempo de reação de algumas dezenas de milisegundos pela ocorrência de um estímulo visual ou auditivo precedendo o 
estímulo alvo visual. O efeito facilitador observado foi o máximo, considerando os achados de Davis e Green (1969) e Muller-Gethmann, Ulrich e Rinkenauer (2003).

Pinheiro (2006) obteve no experimento com tarefa de tempo de reação simples uma evidência de interação da estimulação precedente e a intensidade do alvo, o que sugere uma ação facilitadora do estímulo precedente auditivo na etapa sensorial ou em etapa sensório-motora do processamento. Hackley e Valle-Inclán (2003), Leuthold (2003), Muller-Gethmann, Ulrich e Rinkenauer (2003) avaliaram potenciais corticais relacionados com eventos, especialmente o potencial de prontidão lateralizado. Também concluíram que a influência facilitadora de um estímulo precedente modularia etapas anteriores ao processamento motor, ou seja, a etapa sensorial e/ou de integração sensório-motora. Posteriormente, Correa, Lupiáñez e Tudela (2005) fizeram uso da teoria de detecção de sinal e obtiveram evidências de que a focalização da atenção em intervalos temporais promove melhora do desempenho de processos perceptivos.

Cardoso-Leite, Mamassian e Gorea (2009) descrevem a proposta de que decisões sensoriais ou motoras operam no mesmo modelo interno para respostas, mas em diferentes momentos e níveis de ativações internas. Fazem uma citação ao trabalho de Sternberg e Knoll (1973) no qual propõem que as respostas motoras são disparadas pela ativação neural evocada pelo estímulo que atinge o limiar para respostas motoras, enquanto que os julgamentos perceptivos ocorreriam no intervalo temporal entre os valores de pico dessas respostas internas evocadas.

Para Cardoso-Leite, Mamassian e Gorea (2009) as variações nas respostas motoras ou perceptivas diminuiriam na proporção da intensidade dos estímulos e aumentariam de acordo com a construção dessas respostas ao longo do tempo. Ressalta, portanto, o processo de decisão motora e perceptiva envolvido nessas relações.

Pinheiro (2006) não observou qualquer interação da estimulação precedente e a extensão da resposta motora, nem facilitação pelo estímulo precedente auditivo do tempo para executar os movimentos de flexão em resposta ao alvo. Estes achados são contrários à idéia de que a ação facilitadora do estímulo precedente auditivo ocorra na etapa motora do processamento visuo-motor, em oposição às conclusões de Coull et al. (1999, 2000). Para estes autores a estimulação precedente promoveria especificamente uma preparação motora. 
Com base na sugestão de uma ação facilitadora do estímulo precedente auditivo na etapa sensorial, ou em uma etapa integrativa do processamento visuomotor, tornou-se relevante confirmar esse achado.

\subsection{Envolvimento de mecanismos sensoriais no efeito facilitador do estímulo precedente}

Vários autores defendem na literatura o envolvimento dos processos perceptivos no efeito facilitador proporcionado pelo estímulo precedente na orientação temporal (CORREA; LUPIÁÑEZ ; TUDELA, 2005; CORREA, et al, 2006; LANGE e RÖDER, 2006; LANGE; RÖSLER; RÖDER, 2003; ROLKE e HOFMANN, 2007; SANDERS e ASTHEIMER, 2008). Outros defendem o envolvimento de processos motores (CORREA e NOBRE, 2008; COULL et al, 2000; MINIUSSI et al, 1999; MULLER-GETHMANN; ULRICH; RINKENAUER, 2003).

Recentemente, Correa et al (2010) investigaram se a orientação temporal pode facilitar o controle executivo e encontram evidências de que o efeito facilitador pode modular o processamento de estímulos para a preparação da resposta, porém não conseguem definir como a orientação temporal influência o controle executivo.

Considerando a existência de ainda alguma controvérsia sobre os mecanismos neurais envolvidos no efeito facilitador proporcionado pelo estímulo precedente e os achados obtidos em experimentos anteriores, o presente trabalho se propõe a reexaminar esta questão, particularmente a contribuição relativa dos processos sensoriais.

O objetivo deste trabalho foi, portanto, verificar a contribuição relativa de processos sensoriais na facilitação proporcionada pelo estímulo precedente auditivo. Para esta análise foram realizados dois experimentos. O Experimento 1 consistiu em um experimento de tempo de reação simples, nos quais os estímulos alvos visuais foram apresentados em diferentes níveis de dificuldade de detecção e de maneira randomizada. $\mathrm{O}$ experimento 2 consistiu em uma tarefa de acurácia, na qual deveria ser feita e detecção de estímulo visual e cujos resultados foram submetidos à análise da teoria de detecção de sinal (ANEXO A). Em ambos experimentos houve a presença de estímulo precedente auditivo.

O primeiro experimento visou avaliar em que medida o efeito facilitador é ampliado quando a dificuldade sensorial varia ao longo de um mesmo bloco de 
tentativas, em uma tarefa de tempo de reação simples. Acreditava-se que este procedimento fosse mais eficiente que o empregado anteriormente por Pinheiro (2006) para evidenciar uma interação da estimulação precedente e a intensidade do alvo, uma vez que se uniformizam a estratégia atencional e o critério adotado pelo voluntário, fatores importantes na determinação da responsividade. Neste primeiro experimento foi utilizado o método de fatores aditivos de Sternberg pela possibilidade de mudança nas condições experimentais, de modo a envolver mais um determinado estágio do processamento, de acordo com a variável controlada. $A$ ocorrência de maior facilitação para estímulos mais difíceis indicaria se a etapa sensorial seria a responsável pelo efeito facilitador do estímulo precedente auditivo.

Devido ao fato de tarefas de tempo de reação simples e tempo de reação de escolha envolverem complexidades diferentes do processamento sensorial e sensório-motor (KLAPP, 1995; MILLER e ANBAR, 1981), inicialmente foi pensado em realizar os dois modelos de tarefa. Entretanto, os resultados do primeiro experimento, realizado com a tarefa de tempo de reação simples, desestimularam a realização subseqüente do experimento em que a tarefa de tempo de reação de escolha seria empregada, uma vez que não foi encontrada evidência do estímulo precedente exercer sua influência facilitadora sobre mecanismos sensoriais.

Em busca de uma resposta para a origem fisiológica da influência facilitadora do estímulo precedente, houve mudança no método psicofísico de investigação. No segundo experimento, a teoria de detecção de sinal utilizada para avaliar em que medida a influência facilitadora do estímulo precedente auditivo melhora a detectabilidade e diminui o critério de resposta, caracterizando uma facilitação por processos sensoriais. Foi apresentado um estímulo alvo com intensidade próximo ao limiar sensório. Este estímulo deveria ser detectado pelo observador. Foram consideradas as alterações na detectabilidade (d') e no critério (C) frente a presença do estímulo precedente. Uma alteração (aumento) da detectabilidade e não do critério reforçaria a hipótese da contribuição sensorial na facilitação proporcionada pelo estímulo precedente. 


\section{EXPERIMENTO 1}

O primeiro experimento foi realizado com o propósito de evidenciar a influência facilitadora do estímulo precedente sobre processos sensoriais, seguindo o mesmo modelo experimental do primeiro experimento realizado por Pinheiro (2006). Esperava-se encontrar uma interação da presença do estímulo precedente auditivo com a dificuldade em detectar o estímulo alvo, o que indicaria um maior benefício do som quanto maior fosse a dificuldade em detectar o estímulo alvo visual e, portanto, apontaria para uma facilitação operando em processos sensoriais. $O$ experimento diferenciou-se dos experimentos anteriores pela randomização da exposição das diferentes luminâncias em um mesmo bloco de tentativas, a fim de evidenciar o efeito.

Neste experimento foi realizada uma tarefa de tempo de reação simples (TRS) e com quatro intensidades do estímulo alvo, correspondente às luminâncias 2,5, 5,0,10,0 e 20,0 cd/ $\mathrm{m}^{2}$, apresentadas de maneira randomizada dentro de cada bloco de tentativas. A resposta poderia ser realizada com ambas as mãos. De acordo com o método de fatores aditivos, a obtenção de uma interação dos fatores intensidade do estímulo alvo e presença do estímulo precedente auditivo indicaria que a influência facilitadora do som ocorreria sobre a etapa sensorial do processamento sensório-motor.

A realização de uma tarefa de TRS com apresentação randomizada dos estímulos visuais em cada bloco, poderia manter uma ênfase maior em processos sensoriais ao mesmo tempo em que aumentasse a sua dificuldade de detecção do estímulo alvo. Esperava-se que a interação entre o som e a dificuldade de detecção do alvo se evidenciasse.

Adicionalmente foi realizada a análise de compatibilidade entre a mão de resposta e o local de aparecimento do estímulo alvo. Em geral, o tempo de reação é menor quando o lado da resposta requerida corresponde ao lado do estímulo alvo, condição dita compatível, do que quando o lado da resposta não coincide com o do estímulo alvo, condição dita incompatível.

Quando há correspondência entre a codificação espacial do estímulo e a codificação espacial da resposta, esta tende a ser emitida mais rapidamente do que quando não há tal correspondência, como em uma condição incompatível. 0 
processo de seleção de resposta que envolve as condições de compatibilidade/incompatibilidade possibilita a observação do efeito do estímulo precedente sobre processos sensório-motores.

\subsection{Material e métodos}

\subsubsection{Participantes}

Participaram 12 mulheres adulto-jovens (18 a 30 anos), destras, segundo 0 Questionário de Edinburgh (OLDFIELD, 1971), ANEXO B, com visão normal ou corrigida para o normal e audição normal. As voluntárias foram submetidas ao teste de acuidade visual por meio da identificação correta de letras ou números presentes em uma tabela de leitura, posicionada a $50 \mathrm{~cm}$ de distância dos seus olhos (ANEXO C). O teste de acuidade auditiva foi aplicado na própria sala de experimentos. Para este teste, a voluntária ficou na mesma posição de teste experimental e respondeu positivamente após ser emitido o estímulo auditivo. Este foi na freqüência de 1000 $\mathrm{Hz}$, intensidade de $52 \mathrm{~dB}$ e duração de $50 \mathrm{~ms}$. Primeiramente foi testada a audição do ouvido direito e em seguida a do esquerdo, através do bloqueio manual alternado. Estes indivíduos eram inexperientes em relação a tarefa a ser realizada.

O projeto de pesquisa foi aprovado Comissão de Ética em Pesquisa com Seres Humanos do Instituto de Ciências Biomédicas da Universidade de São Paulo.

\subsubsection{Material}

Os voluntários foram testados individualmente em uma sala com baixo nível de iluminação e com isolamento acústico parcial. Eles permaneceram sentados, em frente a uma mesa, com a cabeça apoiada sobre um suporte de fronte e mento (Figura 6). Seus olhos ficaram a uma distância de $57 \mathrm{~cm}$ da tela de um monitor de vídeo de 17 polegadas, na qual foram apresentados os estímulos alvos visuais (E2). Os estímulos precedentes auditivos foram produzidos pelo auto-falante do computador. A intensidade desses estímulos foi de $52 \mathrm{~dB}$, sendo verificada com o decibelímetro modelo MSL - 1351C, IEC 651, TYPE II, utilizando os seguintes parâmetros: resposta FAST (fonte de som com somente um pico sonoro), 
ponderação $A$ (nível de ruído geral) e faixa de 30-80 dB. A freqüência utilizada foi de $1000 \mathrm{~Hz}$, por corresponder a freqüência de melhor sensibilidade auditiva.

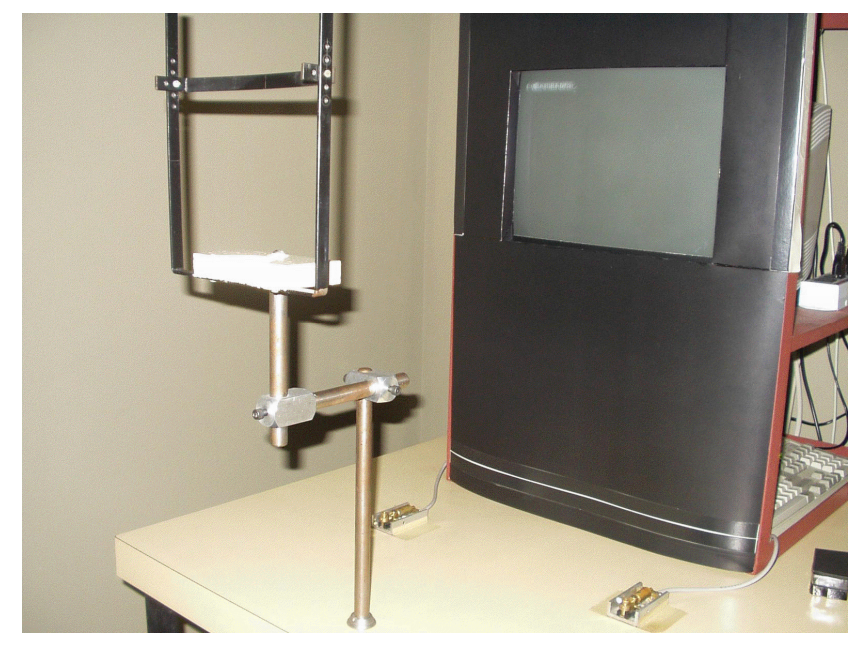

Figura 6: Disposição esquemática dos materiais utilizados na realização dos experimentos.

Seus dedos indicadores ficaram encostados em uma tecla localizada sobre a mesa, sendo uma do seu lado esquerdo e outra do seu lado direito. A resposta consistiu em pressionar a tecla da esquerda ou da direita, conforme orientação recebida, o mais rápido possível.

Os estímulos foram gerados $\mathrm{e}$ as respostas gravadas por um microcomputador IBM-PC/AT 486, controlado por um programa elaborado com 0 aplicativo MEL2 - Micro Experimental Laboratory (Psychology Software Tools). A sinalização das respostas ao computador foi feita por meio de uma interface construída pelo Engenheiro Adhemar Petri Filho. Os parâmetros temporais da situação estimulatória e as medidas de tempo de reação tiveram uma precisão da ordem de um milésimo de segundo.

\subsubsection{Procedimento}

O grupo de voluntários que realizou este experimento teve a luminância dos estímulos alvos apresentada com os valores de 2,5, 5,0, 10,0 e 20,0 cd/ $/ \mathrm{m}^{2}$, apresentadas de maneira randomizada em cada bloco de tentativas. A resposta motora consistiu de um único pressionamento da tecla o mais rápido possível. 
Cada voluntário participou de duas sessões de testes, realizadas em dias separados, porém não excedendo sete dias entre uma e outra. A primeira sessão teve a função exclusiva de familiarizar o voluntário com todo o procedimento experimental. $O$ voluntário que concordasse em participar do estudo assinava 0 termo de consentimento livre e esclarecido (ANEXO D), documento exigido pela Comissão de Ética em Pesquisa com Seres Humanos.

Antes de ser iniciada a primeira sessão, o voluntário recebeu instruções por escrito (ANEXO E), fora da sala de experimento, e verbais no interior da mesma. Nessa sessão houve oito blocos de tentativas, sendo quatro blocos respondidos com a mão direita e os outros quatro respondidos com a mão esquerda, em um total de 18 tentativas por bloco, sem a presença de estímulo auditivo (E1). A segunda sessão forneceu os dados que foram analisados e também foi composta por oito blocos de tentativas, porém com 36 tentativas em cada um, separados por um pequeno intervalo de descanso, presença de E1 e de "pegadas" (situação em que se tem presença do E1 e ausência do E2). Nos intervalos, em ambas as sessões, o examinador foi chamado para fazer o registro do tempo de reação e do número de erros, bem como para fornecer novas orientações (quando necessárias).

Cada tentativa iniciou-se com o aparecimento de um ponto branco no centro da tela de fundo cinza escuro. Este ponto correspondeu ao ponto de fixação (PF), no qual a voluntária fixava os olhos. Em $60 \%$ das tentativas, entre 2000 e 3000 ms depois, foi apresentado o $\mathrm{E} 1$ (tom de $1000 \mathrm{~Hz}$, com $52 \mathrm{~dB}$ de intensidade e $50 \mathrm{~ms}$ de duração). A variação do momento de apresentação teve como propósito minimizar a preparação para o E1. Em dois terços dessas tentativas, $200 \mathrm{~ms}$ depois (tempo necessário para melhor preparação temporal) foi apresentado o E2, correspondente a um disco branco ou variação de tonalidades de cinza (aumento da complexidade para percepção) com $0,50^{\circ}$ de diâmetro, duração de $100 \mathrm{~ms}, 0,75^{\circ}$ à esquerda ou à direita do ponto de fixação (representado pela mesma Figura 7 e 8 ). $O$ terço restante não foi seguido pelo E2, correspondendo ao teste de "pegada", com a finalidade de certificar que o voluntário estivesse respondendo ao alvo e não ao E1. Em 40\% das tentativas, apenas foi apresentado o E2. 


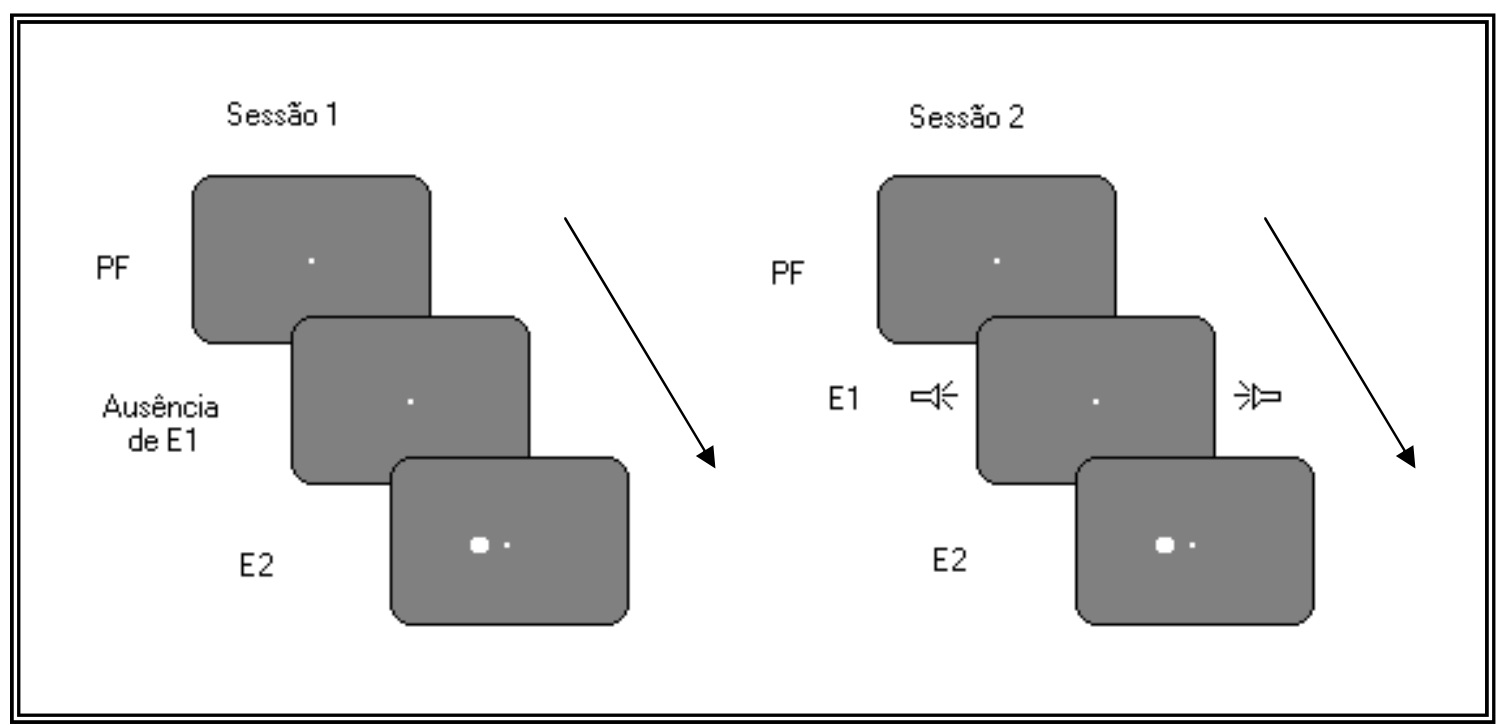

Figura 7: Representação esquemática da apresentação dos estímulos na primeira e na segunda sessão. O E2 foi apresentado à direita ou à esquerda do ponto de fixação, em tentativas diferentes.

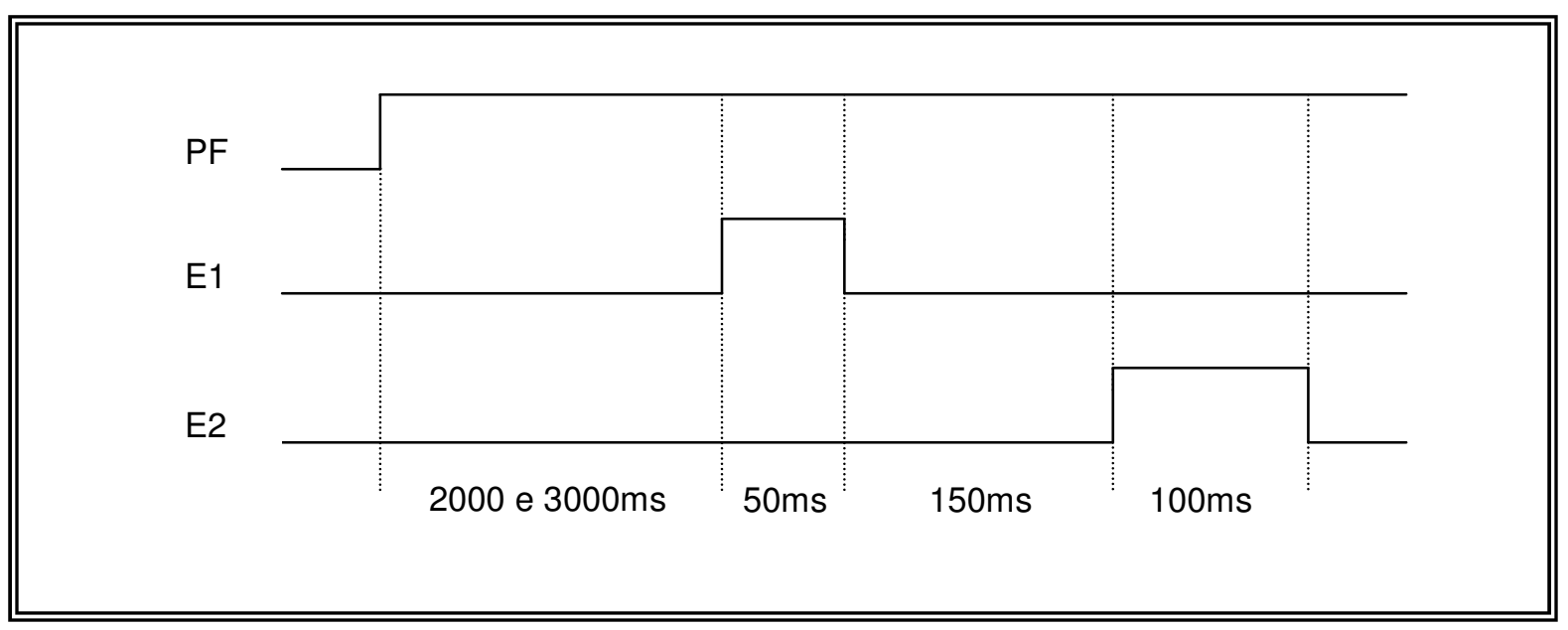

Figura 8: Representação esquemática do padrão temporal da estimulação auditiva (E1) e visual (E2). 
O voluntário respondia ao estímulo alvo com a mão direita, independente do lado do aparecimento do E2 em quatro blocos de tentativas e com a mão esquerda em outros quatro blocos. A tentativa terminava com uma mensagem sobre o desempenho do voluntário, durando 200 ms no local fixado. Na primeira sessão, a mensagem sobre o tempo de reação, em milisegundos, aparecia quando o voluntário respondia entre 150 e 1000 ms após o início do estímulo alvo. Esta mensagem era apresentada na cor verde. A mensagem "ANTECIPADA" ou "LENTA" aparecia respectivamente quando o voluntário respondia em menos de $150 \mathrm{~ms}$ depois do início do estímulo alvo e mais de 1000 ms depois do início do estímulo alvo. Quando o voluntário respondia na ausência de E2 ("pegada"), aparecia a mensagem "INCORRETA". Essas três últimas mensagens eram apresentadas na cor vermelha.

Na segunda sessão, a informação sobre o tempo de reação, que corresponde a uma resposta correta, foi substituída por um ASTERISCO VERDE, e as mensagens ANTECIPADA, LENTA e INCORRETA foram substituídas por um ASTERISCO VERMELHO. Os testes errados foram repostos nas duas sessões. O término dessa sessão foi acompanhado pelo preenchimento do Questionário de Edinburgh (OLDFIELD, 1971), realização dos testes de acuidade visual, acuidade auditiva e de daltonismo (ANEXO F).

\subsection{Análise estatística}

Para cada participante foi calculada a mediana dos tempos de reação em cada bloco e para cada condição, incluindo a mão de resposta (ANEXO G). Também foi avaliado o número de erros de antecipação, de omissão e de comissão (resposta na ausência de E2). Apenas os dados da segunda sessão de teste foram considerados.

Os dados de tempo de reação foram submetidos a uma primeira análise de variância para medidas repetidas, tendo como fatores a mão de resposta, a estimulação precedente (ausente ou presente) e a luminância do estímulo alvo $(2,5$, $5,0,10,0$ e $\left.20,0 \mathrm{~cd} / \mathrm{m}^{2}\right)$.

Em uma segunda análise de variância o fator mão de resposta foi ignorado e o fator compatibilidade estímulo-resposta foi considerado. Quando apropriado, os 
dados foram analisados adicionalmente com o teste de Newman-Keuls. O nível de signoficância adotado foi de 0,05. Os dados de acurácia foram submetidos ao teste de Wilcoxon.

\subsection{Resultados}

\subsubsection{Tempo de reação}

Os tempos de reação encontrados nas diferentes condições estão apresentados na Tabela 1. A análise de variância evidenciou efeito principal para o fator luminância $\left(F_{3,33}=51,980 ; p<0,001\right)$ e estímulo precedente $\left(F_{1,11}=65,199 ; p\right.$ $<0,001)$. Houve diferença no tempo de reação entre as quatro luminâncias. O tempo de reação na condição com estímulo precedente (com som - CS) foi menor do que na condição sem estímulo precedente (sem som - SS). Não houve efeito principal para o fator mão $\left(F_{1,11}=0,478 ; p=0,50\right)$, indicando que as duas mãos exibiram tempos de reação semelhantes.

Tabela 1 - Média dos tempos de reação ( média \pm e.p.m.) em milisegundos das mãos esquerda e direita, nas condições sem som (SS) e com som (CS), para as diferentes luminâncias do estímulo alvo $(20,0,10,0,5,0$ e 2,5 cd/m2).

\begin{tabular}{|c|c|c|c|c|c|c|c|c|}
\hline \multirow[t]{3}{*}{ Mão } & \multicolumn{8}{|c|}{ Luminância $\left(\mathrm{cd} / \mathrm{m}^{2}\right)$} \\
\hline & \multicolumn{2}{|c|}{20} & \multicolumn{2}{|c|}{10} & \multicolumn{2}{|c|}{5} & \multicolumn{2}{|c|}{2.5} \\
\hline & SS & CS & SS & CS & SS & CS & SS & CS \\
\hline Esquerda & $332 \pm 7$ & $282 \pm 11$ & $333 \pm 8$ & $281 \pm 8$ & $342 \pm 8$ & $291 \pm 8$ & $361 \pm 9$ & $304 \pm 6$ \\
\hline Direita & $332 \pm 8$ & $283 \pm 7$ & $337 \pm 6$ & $285 \pm 8$ & $344 \pm 7$ & $290 \pm 7$ & $356 \pm 9$ & $310 \pm 9$ \\
\hline
\end{tabular}

Conforme pode ser observado na Tabela 2, não houve qualquer interação dos fatores considerados. 
Tabela 2 - Resultados da análise de variância tendo como fatores a luminância do estímulo alvo $(20,0,10,0,5,0$ e 2,5 cd/m2 ), o estímulo precedente-E1 (ausente ou presente) e a mão (esquerda ou direita). Os resultados significantes estão indicados com um asterisco $\left(^{*}\right)$. $(\mathrm{Gl}=$ graus de liberdade; $\mathrm{F}=$ razão entre 0 quadrado da média do efeito e o do erro; $p$ = nível de significância).

\begin{tabular}{llll}
\hline \hline EFEITO & GI & F & P \\
\hline Luminância & 3,33 & $51,980^{*}$ & $<0,001^{*}$ \\
E1 & 1,11 & $65,199^{*}$ & $<0,001^{*}$ \\
Mão & 1,11 & 0,478 & 0,503 \\
Luminância x E1 & 3,33 & 0,088 & 0,966 \\
Luminância x Mão & 3,33 & 0,256 & 0,856 \\
E1 x Mão & 1,11 & 0,388 & 0,546 \\
Luminância x E1 x Mão & 3,33 & 0,751 & 0,529 \\
\hline \hline
\end{tabular}

A análise post hoc do fator luminância revelou que o tempo de reação foi maior para a luminância de $5,0 \mathrm{~cd} / \mathrm{m}^{2}$ do que para a de $20,0 \mathrm{~cd} / \mathrm{m}^{2}(\mathrm{p}<0,001)$ e 10,0 $\mathrm{cd} / \mathrm{m}^{2}(\mathrm{p}=0,002)$ e maior para a luminância de $2,5 \mathrm{~cd} / \mathrm{m}^{2}$ do que para as luminâncias de $20,0 \mathrm{~cd} / \mathrm{m}^{2}$ ( $\left.<<0,001\right), 10,0 \mathrm{~cd} / \mathrm{m}^{2}$ (p<0,001) e $5,0 \mathrm{~cd} / \mathrm{m}^{2}$ (p< 0,001).

A figura 9 ilustra a influência da luminância do estímulo alvo e da estimulação sonora sobre o desempenho. Houve forte evidência do esperado efeito do aumento do tempo de reação na medida em que havia redução da luminância do estímulo alvo. O estímulo sonoro reduziu de modo importante o tempo de reação em todas as luminâncias do estímulo alvo. 


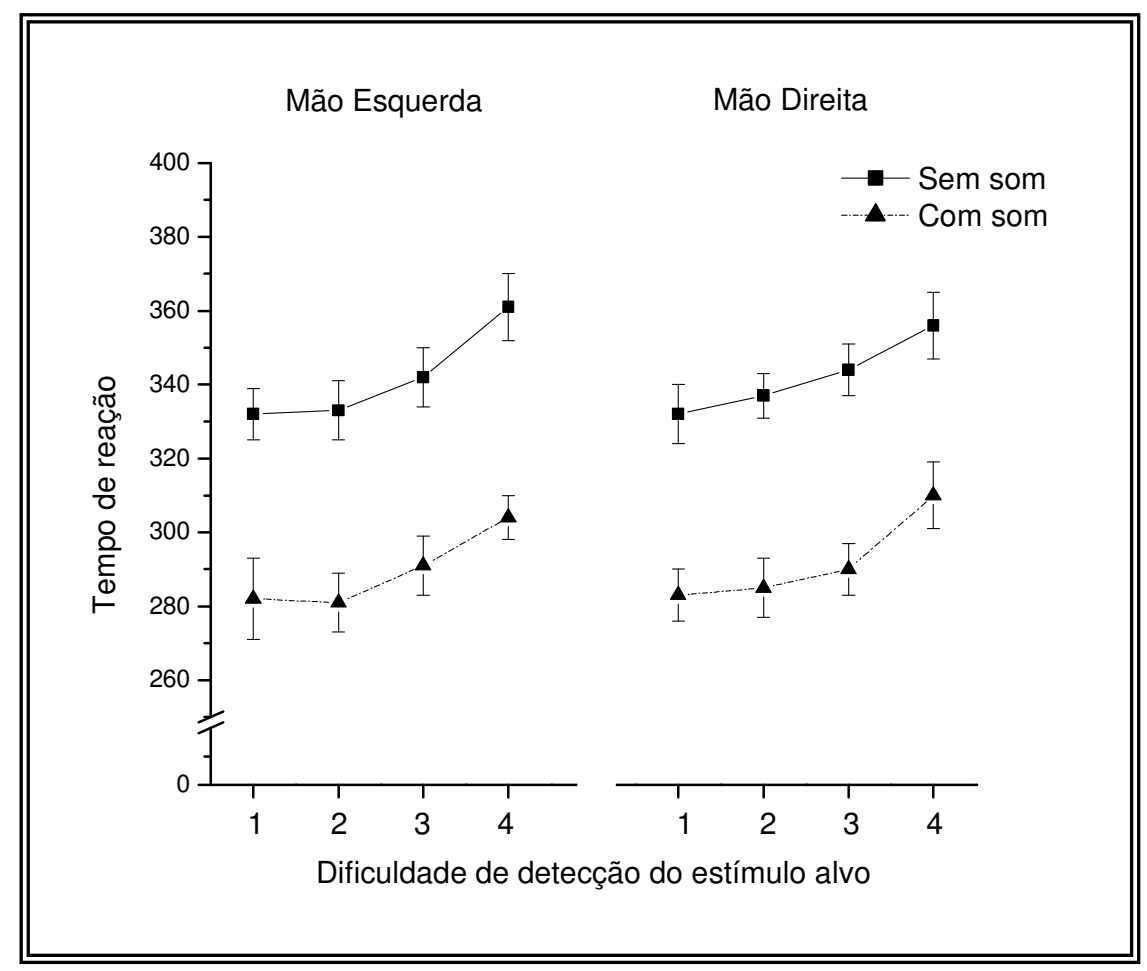

Figura 9: Tempo de reação (média \pm e.p.m.) em milisegundos, das mãos esquerda e direita, nas condições sem som e com som para as dificuldades $1(20,0 \mathrm{~cd} / \mathrm{m} 2), 2$ (10,0 cd/m2), $3(5,0 \mathrm{~cd} / \mathrm{m} 2)$ e $4(2,5 \mathrm{~cd} / \mathrm{m} 2)$ de detecção do estímulo alvo.

Em razão da ausência de diferença significante entre mãos, os dados das duas mãos foram agrupados. A figura 10 ilustra os resultados encontrados sem distinção da mão utilizada para responder. 


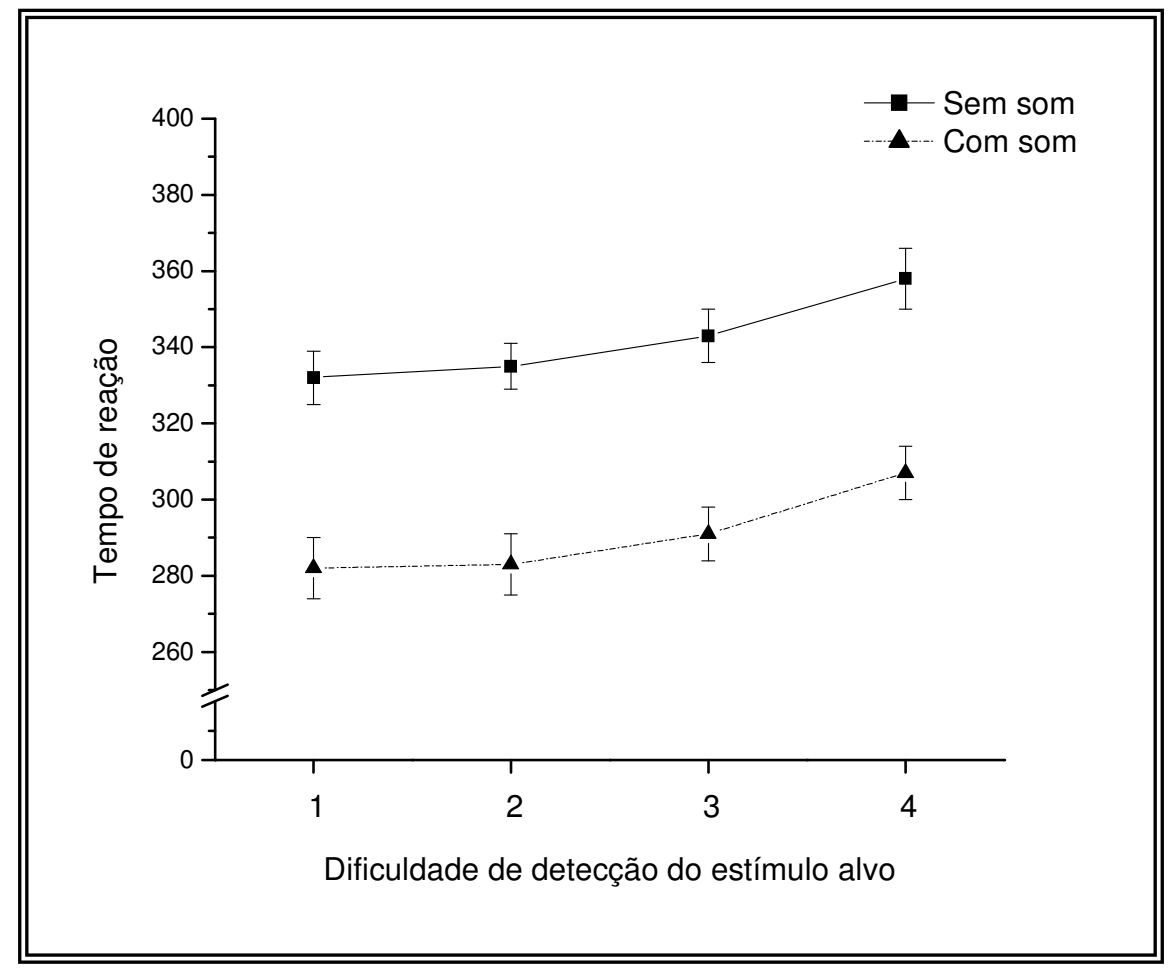

Figura 10: Tempo de reação (média \pm e.p.m.) em milisegundos, sem distinção de mão, nas condições sem som e com som para as dificuldades 1 (20,0 cd/m2), 2 (10,0 $\mathrm{cd} / \mathrm{m} 2)$, $3(5,0 \mathrm{~cd} / \mathrm{m} 2)$ e $4(2,5 \mathrm{~cd} / \mathrm{m} 2)$ de detecção do estímulo alvo.

A Tabela 3 apresenta a média do tempo de reação para as condições de compatibilidade entre E2 e mão de resposta, as quatro condições de luminâncias e as condições de estimulação precedente (SS e CS).

Tabela 3 - Média dos tempos de reação (média \pm e.p.m.) em milisegundos para as condições entre estímulo alvo e mão de resposta compatível e incompatível, nas condições sem som e com som, para as diferentes luminâncias do estímulo alvo.

\section{Luminância $\left(\mathrm{cd} / \mathrm{m}^{2}\right)$}

\begin{tabular}{llll}
\hline 20 & 10 & 5 & 2.5
\end{tabular}

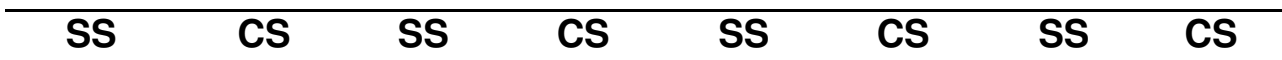

\begin{tabular}{lllllllll}
\hline Compatível & $329 \pm 8$ & $282 \pm 10$ & $337 \pm 7$ & $279 \pm 8$ & $339 \pm 8$ & $288 \pm 7$ & $357 \pm 9$ & $302 \pm 7$ \\
Incompatível & $335 \pm 8$ & $283 \pm 8$ & $333 \pm 7$ & $287 \pm 8$ & $345 \pm 7$ & $293 \pm 8$ & $360 \pm 9$ & $312 \pm 8$
\end{tabular}


A segunda análise de variância planejada revelou efeito principal para os fatores compatibilidade $\left(F_{1,11}=7,795 ; p=0,017\right)$, luminância $\left(F_{3,33}=51,974 ; p<\right.$ $0,001)$ e estímulo precedente $\left(F_{1,11}=65,201 ; p<0,001\right)$. Houve diferença no tempo de reação entre as quatro luminâncias. O tempo de reação na condição com estímulo precedente (com som - CS) foi menor do que na condição sem estímulo precedente (sem som - SS).

A Tabela 4 possibilita visualizar esses resultados, bem como a ausência de interação entre os fatores.

Tabela 4 - Resultados da análise de variância tendo como fatores a compatibilidade entre estímulo alvo e mão de resposta (compatível ou incompatível), luminâncias do estímulo alvo (20,0, 10,0, 5,0 e 2,5 cd/m2 ) e o estímulo precedente-E1 (ausente ou presente). Os resultados significantes estão indicados com um asterisco $\left({ }^{*}\right)$. $(\mathrm{Gl}=$ graus de liberdade; $\mathrm{F}=$ razão entre o quadrado da média do efeito e o do erro; $p$ = nível de significância).

\begin{tabular}{llll}
\hline \hline EFEITO & GI & F & P \\
\hline Compatibilidade & 1,11 & $7,795^{*}$ & $<0,017^{*}$ \\
Luminância & 3,33 & $51,974^{*}$ & $<0,001^{*}$ \\
E1 & 1,11 & $65,201^{*}$ & $<0,001^{*}$ \\
Compatibilidade x Luminância & 3,33 & 0,750 & 0,530 \\
Compatibilidade x E1 & 1,11 & 0,523 & 0,485 \\
Luminância x E1 & 3,33 & 0,088 & 0,966 \\
Compatibilidadex Luminância x E1 & 3,33 & 1,385 & 0,265 \\
\hline \hline
\end{tabular}

A análise post hoc do fator compatibilidade evidenciou que o tempo de reação foi maior para a condição incompatível do que para a compatível. Enquanto que para fator luminância revelou que o tempo de reação foi maior para a luminância de 5,0 $\mathrm{cd} / \mathrm{m}^{2}$ do que para a de $20,0 \mathrm{~cd} / \mathrm{m}^{2}(p<0,001)$ e $10,0 \mathrm{~cd} / \mathrm{m}^{2}(p=0,002)$ e maior para a luminância de $2,5 \mathrm{~cd} / \mathrm{m}^{2}$ do que para as luminâncias de $20,0 \mathrm{~cd} / \mathrm{m}^{2}(p<0,001), 10$, $0 \mathrm{~cd} / \mathrm{m}^{2}(p<0,001)$ e $5,0 \mathrm{~cd} / \mathrm{m}^{2}(p<0,001)$.

A figura 11 mostra o aumento do tempo de reação com a redução da luminância do estímulo alvo. O estímulo sonoro reduziu de modo importante o tempo 
de reação em todas as luminâncias do estímulo alvo, tanto para a condição compatível quanto para a condição incompatível.

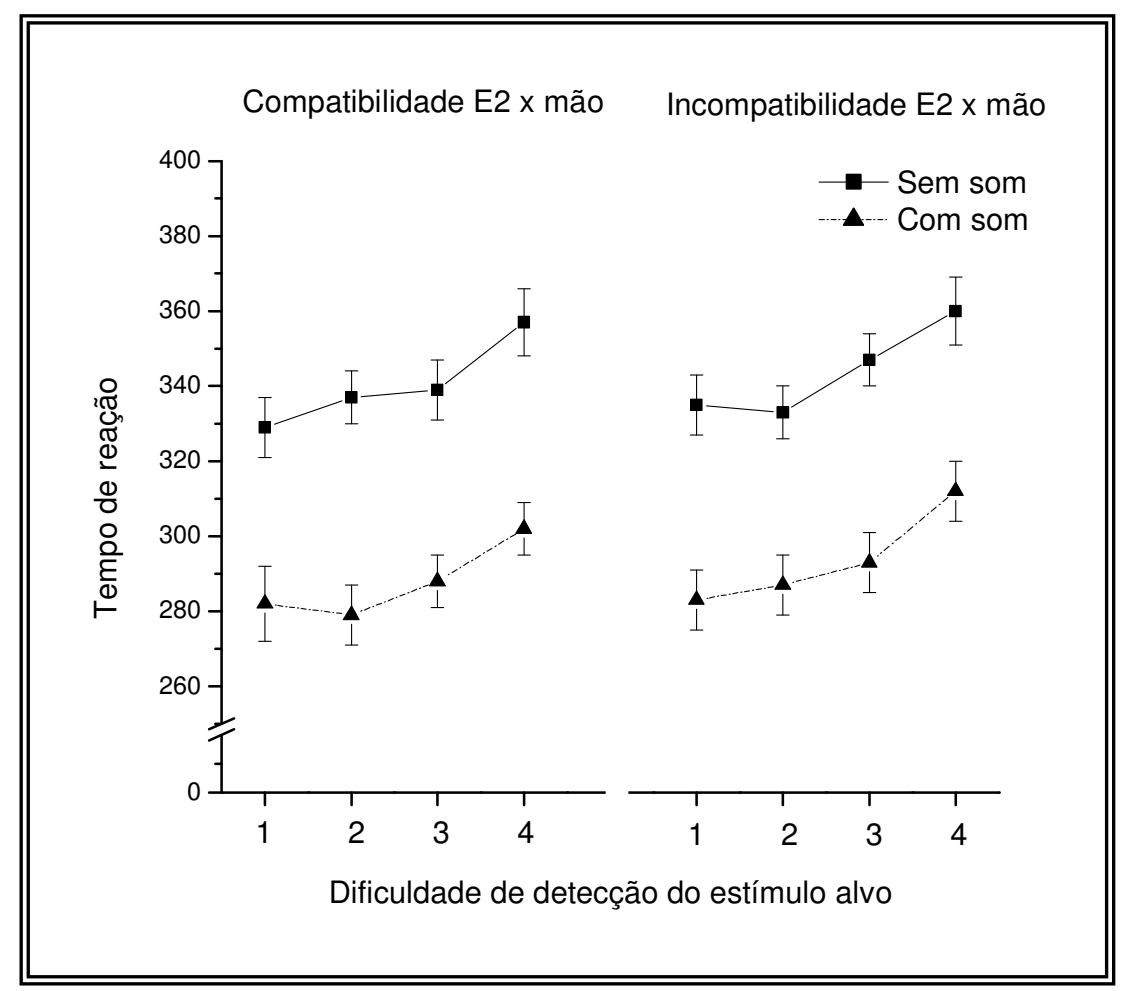

Figura 11: Tempo de reação (média \pm e.p.m.) em milisegundos, na condição compatível e incompatível, nas condições sem som e com som, para as dificuldades 1 (20,0 $\mathrm{cd} / \mathrm{m} 2), 2(10,0 \mathrm{~cd} / \mathrm{m} 2), 3(5,0 \mathrm{~cd} / \mathrm{m} 2)$ e $4(2,5 \mathrm{~cd} / \mathrm{m} 2)$ de detecção do estímulo alvo.

\subsubsection{Acurácia}

Não houve diferença significante no número de erros de antecipação, comissão e omissão, no que se refere a mão de resposta, diferentes luminâncias do estímulo alvo e presença ou ausência do estímulo precedente auditivo.

\subsection{Discussão parcial}

O presente experimento examinou a possibilidade de que o efeito facilitador de um estímulo prévio auditivo sobre o tempo de reação a um estímulo alvo visual pudesse variar de magnitude com a intensidade do estímulo alvo. De acordo com o 
método de fatores aditivos proposto por Sternberg (1969), isto sugeriria que a facilitação se daria na etapa do processamento sensorial.

Houve aumento do tempo de reação com o aumento da dificuldade para detecção do alvo e houve efeito facilitador do estímulo precedente sobre o tempo de reação. Entretanto, não houve qualquer diferença na magnitude desse efeito entre as quatro luminâncias testadas. A diferença marginalmente significante encontrada no primeiro experimento de Pinheiro (2006), no qual as diferentes luminâncias foram apresentadas em blocos separados de tentativas, não foi confirmada.

A apresentação blocada é caracterizada operacionalmente pela utilização de apenas um nível de uma determinada variável em cada bloco. Gera uma baixa incerteza, porque somente um evento pode ocorrer ao longo das tentativas do bloco. A apresentação randomizada dos diferentes níveis da variável promove grande incerteza, pois diferentes eventos podem ocorrer ao longo das tentativas do bloco. No primeiro caso (apresentação blocada) pode ter ocorrido um ajuste específico da atenção para compensar as alterações graduadas do evento relevante. No segundo caso (apresentação randomizada) isto não é possível. Dessa forma, esperava-se que houvesse, no segundo caso, maior favorecimento da responsividade pelo estímulo precedente do que no primeiro caso. Não foi observado, no entanto, um aumento do efeito facilitador com o aumento da dificuldade da detecção do estímulo alvo, mesmo considerando a compatibilidade estímulo-resposta.

A ausência de aumento do efeito facilitador com o aumento da dificuldade de detecção do estímulo alvo é um resultado semelhante ao encontrado no experimento de investigação sensorial desenvolvido anteriormente por Pinheiro (2006). Uma explicação para a ausência da interação é que a dificuldade sensorial apresentada não era suficiente para se beneficiar da facilitação proporcionada pelo estímulo auditivo. 


\section{EXPERIMENTO 2}

A ausência de evidências da influência do efeito facilitador sobre processos sensoriais no experimento 1 levou a busca de uma metodologia que indicasse com mais segurança eventuais alterações no processamento sensorial. Por essa razão, foi desenvolvido um experimento de acurácia, cujos dados foram analisados com base na teoria de detecção de sinal.

$\mathrm{Na}$ teoria de detecção de sinal, a detectabilidade pode aumentar quando $\circ \mathrm{H}$ aumenta ou $F$ diminui. A diferença entre $H$ e $F(H-F)$ representa o aumento da sensibilidade pelo aumento de $\mathrm{H}$ e redução de F. A medida é chamada d' ("deeprime") e é definida nos termos de $z$, a função inversa da distribuição normal:

$$
d^{\prime}=z(H)-z(F) \text {. }
$$

A validade da teoria de detecção de sinal claramente depende da descrição do d' ao representar as mudanças ocorridas em H e F quando o critério é manipulado. De acordo com o modelo da teoria de deteç̧ão de sinal (TDS) ० d' representa a diferença entre a razão transformada de hit e false alarm. Além disso, fornece uma boa descrição da relação entre $\mathrm{H}$ e $\mathrm{F}$ quando o critério varia.

Por interpretação, o critério é a tendência de se responder considerando fatores como preferência para uma determinada resposta, de modo a estar relacionado com o processo decisório.

O d' corresponde a um aspecto fixado da decisão do observador e é representado pela diferença entre $\mathrm{H}$ e F. A medida do critério deve também refletir na característica apropriada da representação perceptiva. $O$ indicador do critério, por sua vez, deve depender da soma dos termos envolvendo H e F. Essa aparente falta de lógica pode ser melhor compreendida quando se representa a medida para calcular o critério:

$$
c=-1 / 2[z(H)+Z(F)]
$$

Se o critério aumenta, o $\mathrm{H}$ e $\mathrm{F}$ irão diminuir. Enquanto que se o critério diminui, H e F aumentam. Muitos hits e poucos false alarms indicam uma maior detectabilidade e, portanto, um maior envolvimento dos mecanismos sensoriais ao invés dos mecanismos envolvidos na tomada de decisão.

O presente experimento consistiu em uma tarefa de escolha forçada e foi realizado em duas etapas. Na primeira etapa foi obtido o limiar visual de cada 
voluntário, por meio da realização do pest, e na segunda etapa foi realizada a tarefa de detecção. Foi calculado o d' (detectabilidade) e o C (critério). Desta forma, o objetivo era verificar se o efeito facilitador do estímulo precedente se dá por meio da contribuição dos processos sensoriais. Em caso afirmativo, esperava-se encontrar o aumento da detectabilidade e redução do critério. Caso os resultados não evidenciassem aumento da detectabilidade e/ou houvesse aumento do critério, não seria confirmada a hipótese de influência sensorial.

\subsection{Material e métodos}

\subsubsection{Participantes}

Foram selecionados 18 voluntários com as mesmas características descritas no experimento 1. Entretanto, o grupo foi composto por 9 homens e 9 mulheres.

\subsubsection{Material}

Utilizou-se o mesmo material do Experimento1.

\subsubsection{Procedimento}

Cada voluntário participava de duas sessões de teste realizadas no mesmo dia. Antes de a sessão ser iniciada, o voluntário recebia instruções por escrito (ANEXO H), fora da sala de experimento e verbais no interior da mesma. A primeira sessão teve a função de familiarizar o voluntário com todo o procedimento experimental e obter o limiar sensório. Este correspondia ao estímulo detectável em $50 \%$ das vezes em que era apresentado. Para determiná-lo foi aplicado o método psicofísico PEST (Parameter Estimation by Sequential Testing), desenvolvido por Taylor e Creelman (1967). O PEST é uma variação do método adaptativo de escada. Consiste na apresentação de estímulos supralimiares e sublimiares, com estímulos apresentados em diferentes intensidades, sem a presença do estímulo auditivo (E1). A programação do seu algoritmo está descrita no ANEXO I.

Cada tentativa foi iniciada com o aparecimento de um ponto branco no centro da tela de fundo cinza escuro. Este ponto correspondia ao ponto de fixação (PF), no 
qual o voluntário fixava o olhar. Entre 2000 e 3000 ms depois era apresentado o estímulo alvo (E2) e era representado por um anel cinza com $0,60^{\circ}$ de diâmetro, duração de 100 ms, em torno do ponto de fixação (Figura 12). O E2 foi apresentado em todas as tentativas.

O teste iniciava com a apresentação de um estímulo com intensidade supralimiar. Havia duas teclas para resposta, posicionadas à direita e à esquerda na mesa à frente do voluntário. O voluntário deveria responder se o estímulo foi apresentado apertando a tecla direita e se julgasse que o estímulo não havia sido apresentado apertava a tecla esquerda. Cada resposta determinava uma mudança na intensidade apresentada, para maior ou menor. A média de aproximadamente 10 vezes que o voluntário mudava a resposta indicativa da apresentação do estímulo visual para a não indicativa de apresentação do estímulo visual, ou vice-versa, determinava o valor do limiar sensório.

A segunda sessão forneceu os dados que foram analisados. Era composta por 2 blocos de tentativas, com 32 tentativas em cada um, separados por um pequeno intervalo de descanso. O E2 tinha a intensidade limiar determinada na primeira sessão. Assim como na primeira sessão, emitia-se a resposta com a mão direita, quando o E2 era detectado e com a mão esquerda quando o E2 não era detectado.

Cada tentativa iniciava com o aparecimento de um ponto branco no centro da tela de fundo cinza escuro. Este ponto correspondia ao ponto de fixação (PF), no qual o voluntário mantinha o olhar fixado. O E2 era apresentado em $50 \%$ das tentativas, sendo que $25 \%$ das vezes em que o E2 foi apresentado houve apresentação do E1 e em 25\% não houve apresentação do E1.

Nos outros 50\% em que não houve apresentação de E2, 25\% destes ocorreu a apresentação de E1 e nos outros 25\% não ocorreu (Tabela 5). Dessa forma, quatro condições foram apresentadas em igualdade de proporção: tentativas sem estímulo precedente auditivo e sem estímulo alvo visual, tentativas com estímulo precedente auditivo e sem estímulo alvo visual, tentativas sem estímulo precedente auditivo e com estímulo alvo visual, tentativas com estímulo precedente auditivo e com estímulo alvo visual. 


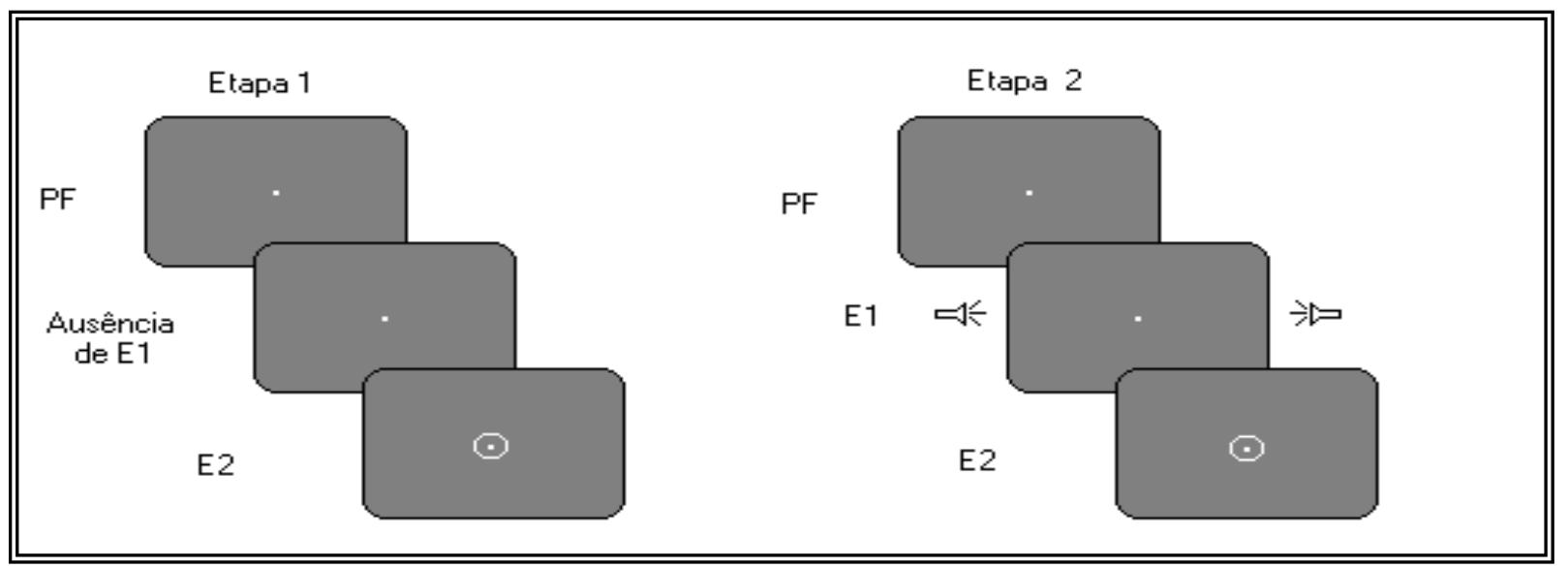

Figura 12: Representação esquemática da apresentação dos estímulos na primeira e na segunda etapa. O E2 (estímulo alvo visual) era apresentado no centro da tela, em torno do ponto de fixação. O E1 (estímulo precedente auditivo) somente era apresentado na segunda etapa.

Tabela 5 - Distribuição das tentativas por cada uma das quatro condições possíveis, de acordo com a presença ou ausência do estímulo precedente auditivo (E1) e com a presença ou ausência do estímulo alvo visual (E2).

\begin{tabular}{c|c|c|c}
\hline \hline \multicolumn{3}{c}{ DISTRIBUIÇÃO DAS TENTATIVAS POR CONDIÇÕES (100\%) } \\
\hline \multicolumn{2}{c|}{ Sem E1 (50\%) } & \multicolumn{2}{c}{ Com E1 (50\%) } \\
\hline Sem E2 (25\%) & Com E2 (25\%) & Sem E2 (25\%) & Com E2 (25\%) \\
\hline \hline
\end{tabular}

Nas tentativas com E2 precedido de E1, entre 2000 e 3000ms depois da apresentação do PF foi apresentado o E1 (tom de $1000 \mathrm{~Hz}$, com $52 \mathrm{~dB}$ de intensidade e $50 \mathrm{~ms}$ de duração). A variação do momento de apresentação se fez importante para minimizar a preparação para o E1. O E2 foi apresentado $200 \mathrm{~ms}$ (tempo necessário para adequada preparação temporal) depois do aparecimento do E1. Este era representado por um anel cinza com $0,60^{\circ}$ de diâmetro, duração de 100 ms, em torno do ponto de fixação.

A tentativa terminava com a mensagem "RESPOSTA?" no centro da tela, emitida após $1000 \mathrm{~ms}$ do desaparecimento do E2. Assim como na primeira etapa, foi emitida a resposta com a mão direita, quando houve o julgamento de presença do E2, e com a mão esquerda, quando houve o julgamento de ausência do E2. Não 
houve um tempo máximo para emissão da resposta, nem solicitação para que o voluntário respondesse o mais rápido possível. O aspecto enfatizado foi a acurácia. Ao final dessa sessão, o voluntário assinou o termo de consentimento livre e esclarecido, documento exigido pela Comissão de Ética em Pesquisa com Seres Humanos, e foi submetido aos testes de acuidade visual e auditiva.

\subsection{Análise estatística}

Para cada voluntário foram avaliadas as porcentagens de acertos (hits), erros (miss), alarme falso (false alarm) e rejeição correta (correct rejection). (GESCHEIDER, 1997; PALMER, 1999; MACMILLAN e CREELMAN, 2005). Com base na teoria de detecção de sinal foram calculados, a partir desses dados (ANEXO J), a detectabilidade ( $d$ ') e o critério ou viés $(C)$, na ausência e na presença do som. Cada um destes parâmetros foi analisado por um teste $T$ para amostras dependentes, usando como nível de significância o valor de 0,05.

\subsection{Resultados}

\subsubsection{Detecção}

O cálculo do limiar sensório foi determinado para cada voluntário e está representado graficamente no ANEXO .

Os dados obtidos na tarefa de detecção estão apresentados na Tabela 6. A análise com teste $\mathrm{T}$ para variáveis dependentes na comparação da detectabilidade indicou diferença entre as condições sem som e com som, com $p=0,01$. Também houve diferença na comparação do critério entre as condições sem som e com som com $\mathrm{p}<0,01$. 
Tabela 6 - Valores de detectabilidade e critério para cada voluntário, nas condições sem som e com som.

\begin{tabular}{|c|c|c|c|c|}
\hline \multirow[t]{2}{*}{ Voluntários } & \multicolumn{2}{|c|}{ Sem som } & \multicolumn{2}{|c|}{$\overline{\text { Com som }}$} \\
\hline & $d^{\prime}$ & $\mathrm{C}$ & $d^{\prime}$ & $\mathrm{C}$ \\
\hline 1 & 2,75 & 0,49 & 3,07 & 0,00 \\
\hline 2 & 2,75 & 0,49 & 3,01 & 0,36 \\
\hline 3 & 0,00 & 0,49 & 0,65 & 1,21 \\
\hline 4 & 2,75 & 0,49 & 3,73 & 0,00 \\
\hline 5 & 0,86 & 1,10 & 0,65 & 1,21 \\
\hline 6 & 2,42 & 0,32 & 3,07 & 0,00 \\
\hline 7 & 1,31 & 0,50 & 2,04 & 0,13 \\
\hline 8 & 2,68 & 0,19 & 3,07 & 0,00 \\
\hline 9 & 0,98 & 1,37 & 1,69 & 0,69 \\
\hline 10 & 3,40 & $-0,16$ & 2,54 & $-0,59$ \\
\hline 11 & 3,40 & 0,16 & 2,75 & 0,49 \\
\hline 12 & 1,85 & 0,61 & 3,40 & 0,16 \\
\hline 13 & 2,54 & 0,59 & 2,21 & 0,43 \\
\hline 14 & 2,35 & 0,69 & 3,07 & 0,00 \\
\hline 15 & 3,73 & 0,00 & 3,73 & 0,00 \\
\hline 16 & 2,75 & 0,49 & 3,73 & 0,00 \\
\hline 17 & 2,68 & 0,19 & 3,40 & $-0,16$ \\
\hline 18 & 2,75 & 0,49 & 3,73 & 0,00 \\
\hline Média & 2,33 & 0,47 & 2,75 & 0,22 \\
\hline Desvio padrão & 0,97 & 0,36 & 0,97 & 0,45 \\
\hline Erro padrão & 0,23 & 0,08 & 0,23 & 0,11 \\
\hline
\end{tabular}

A figura 13 apresenta os dados da variação da detectabilidade na presença do estímulo precedente para cada participante, enquanto a figura 14 representa a média comparativa das condições sem som e com som. 


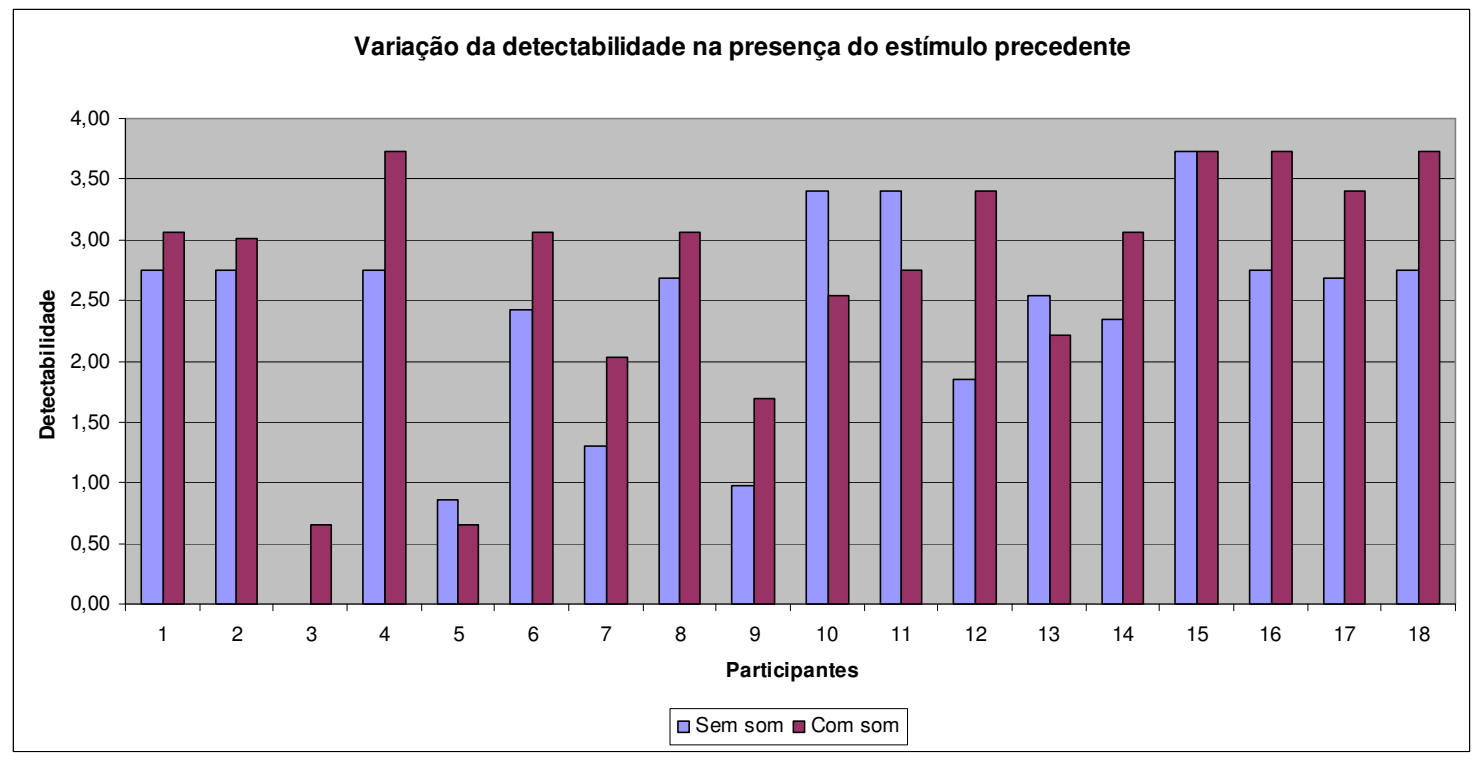

Figura 13: Representação do valor da detectabilidade na condição sem som e com som, para cada participante.

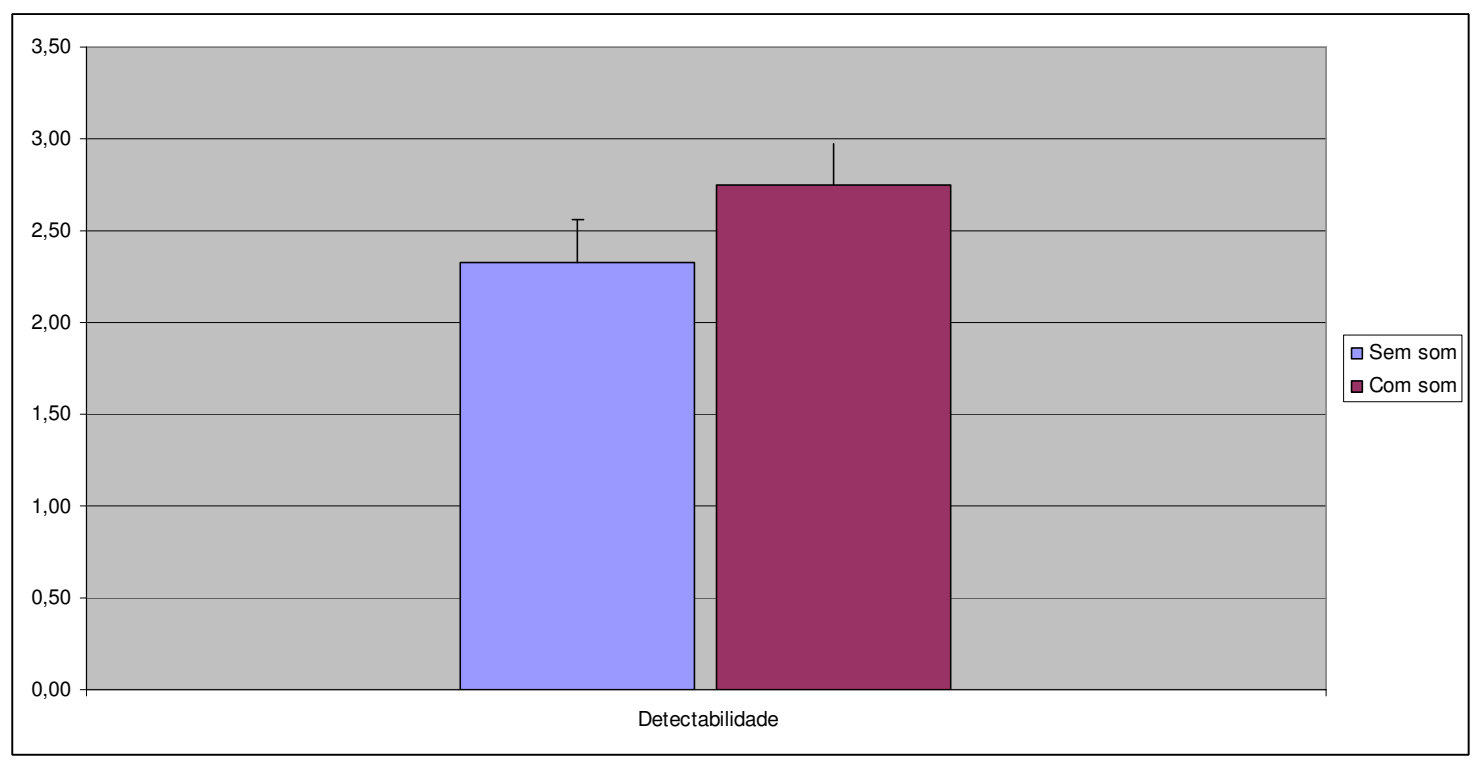

Figura 14: Representação da média da detectabilidade dos participantes na condição sem som e com som, com erro padrão da média.

A figura 15 apresenta os dados da variação do critério na presença do estímulo precedente para cada participante. A figura 16 representa a média dos participantes na análise comparativa das condições sem som e com som. 


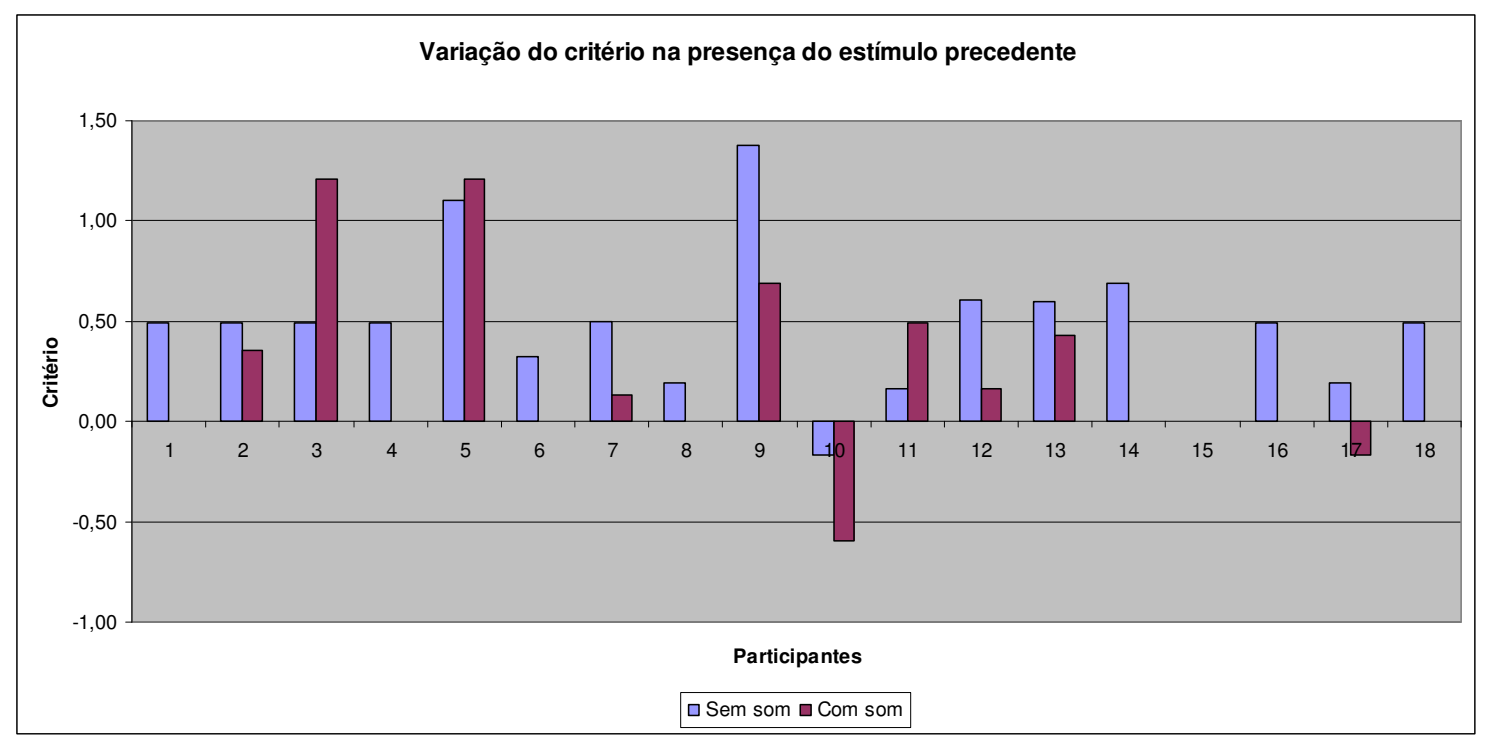

Figura 7: Representação do valor do critério na condição sem som e com som, para cada participante.

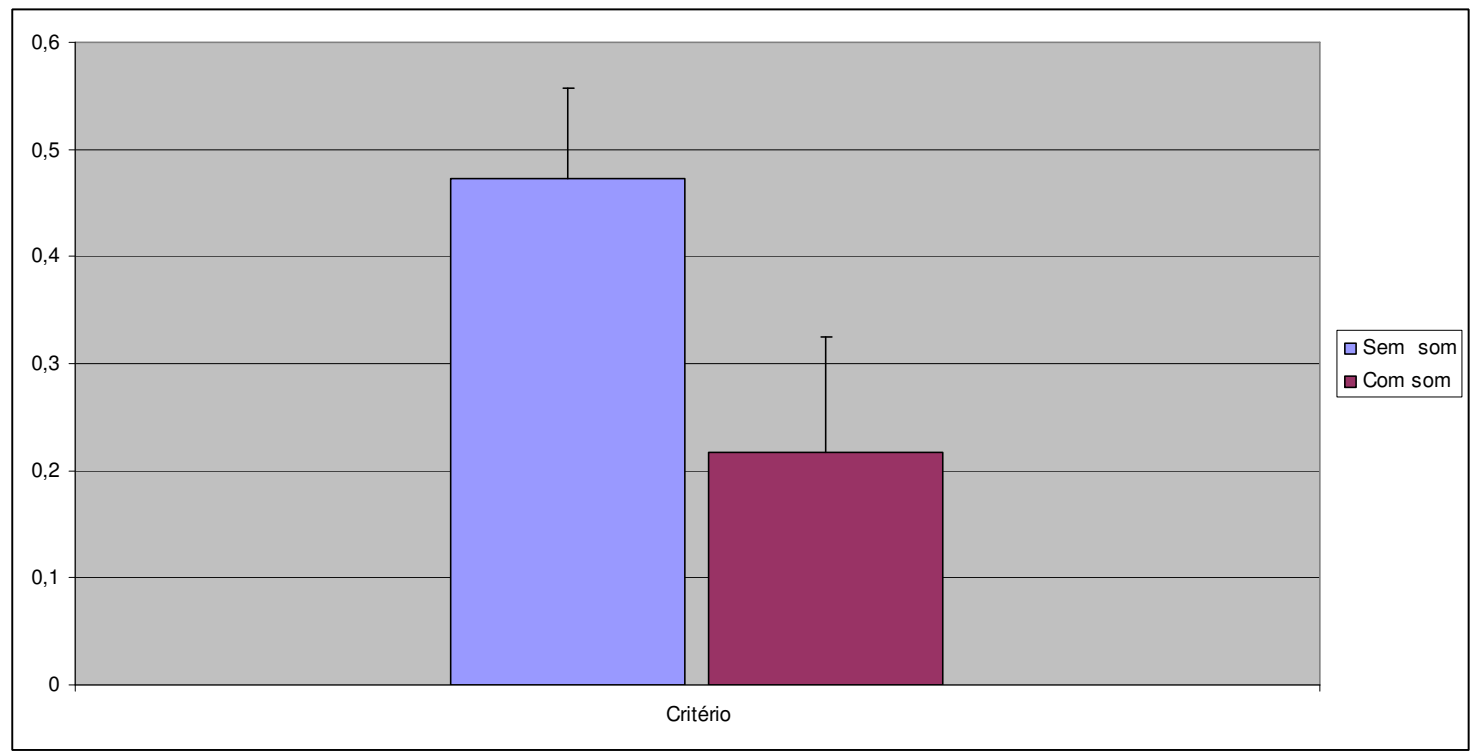

Figura 16: Representação da média do critério dos participantes na condição sem som e com som, com erro padrão da média. 


\subsection{Discussão parcial}

O experimento evidenciou o aumento da detectabilidade (d') e a redução do critério pela presença de um estímulo auditivo. $O$ aumento da detectabilidade indica um processamento sensorial mais eficiente e a redução do critério indica que este ficou mais leniente. Um critério mais leniente sugere menor influencia da estratégia decisional.

A redução do critério na presença do som indica falso alarme alto. Se o d' estivesse reduzido na presença do estímulo precedente, isso poderia ser explicado pelo número elevado de falso alarme. Entretanto, o d' aumentou devido ao aumento significativo no número de acertos.

O aumento da detectabilidade acompanhado com a redução do critério na presença do estímulo precedente auditivo indica que houve melhora da detectabilidade, por meio da melhora do processamento visual, com menor influência de processos decisionais.

$O$ aumento da detectabilidade observado no presente experimento sugere que a atenção temporal proporcione um aumento da eficiência do processamento sensorial, ao invés de um aumento da eficiência do processo decisório (MACMILLAN e CREELMAN, 2005).

Simola, Stenbacka e Vanni (2009) descreveram que a atenção espacial visual melhora a percepção visual para objetos atendidos. Estudos com RNMf indicam que a facilitação ocorre em etapas precoces, ou seja, já no córtex visual primário (V1). Essa inferência tem como base o momento da facilitação das respostas, sendo alterações tardias presumivelmente devidas aos sinais de retroação. Resultados semelhantes de pesquisas anteriores têm sugerido que o circuito de retroação promove a mediação da atividade atencional da resposta em V1. Longas latências de resposta têm sido associadas com seleção atencional precoce, mediada por retroação a partir de áreas corticais superiores. Os achados deste trabalho, portanto, valorizam a idéia de uma atuação da atenção em níveis precoces do processamento sensório-motor.

Os dados encontrados também corroboram a descrição de Pestilli, Viera e Carrasco (2007) da participação dos recursos neurais atencionais com o aumento da eficiência do processamento sensorial. A atenção seria responsável por aumentar a sensibilidade ao contraste e, assim, aumentar as respostas neurais para os 
estímulos atendidos, enquanto que diminui as respostas neurais para os estímulos não atendidos.

Lippert, Logothesis e Kayser (2007) relatam que os efeitos responsáveis pelo melhor desempenho em tarefas de detecção podem ser causados por altas freqüências de disparos das conexões em áreas sensoriais primárias ou em áreas de associação. Descrevem, ainda, que as influências de modalidades cruzadas em tarefas de detecção simples são altas freqüências de disparos em áreas de integração sensorial, sendo preferencialmente ocasionadas por efeitos de ordem cognitivas e atencionais.

Lippert, Logothetis e Kayser (2007) descreveram que a apresentação do som pode melhorar o desempenho em uma tarefa de detecção visual ou aumentar a percepção da luminância de um disparo de luz, mas que a origem desse efeito ainda é alvo de busca por esclarecimentos. A literatura sugere que os aspectos de integração multisensorial estão relacionados às mudanças nas estratégias decisionais e influências cognitivas e que os efeitos responsáveis pelo melhor desempenho da tarefa de detecção podem ser causados por altos disparos das conexões em áreas sensoriais primárias ou por associações formadas pelo processamento em curso. Após realizar experimentos de detecção com apresentação de sons simultâneos em várias tarefas de detecção do contraste, concluíram que as influências de modalidades cruzadas em tarefas de detecção simples são mediadas por altos disparos de integração sensorial, mas preferencialmente são ocasionadas por efeitos de ordem cognitiva e atencionais.

Considerando os dados da literatura e os encontrados neste experimento, há evidências da influência dos processos sensoriais sobre o efeito facilitador do estímulo precedente. 


\section{DISCUSSÃO GERAL}

Os experimentos realizados neste trabalho objetivaram verificar se a melhora no desempenho produzida por um estímulo prévio auditivo poderia se dever a uma facilitação nas etapas sensoriais do processamento sensório-motor. Esta possibilidade tinha como base os resultados de experimentos anteriores, que sugeriam uma ausência de facilitação nas etapas motoras do processamento sensório-motor.

O primeiro experimento verificou se o efeito facilitador de um estímulo prévio auditivo sobre o tempo de reação a um estímulo alvo visual poderia variar de magnitude com a intensidade do estímulo alvo (quatro níveis de luminâncias). De acordo com o método de fatores aditivos proposto por Sternberg (1969), caso isto ocorresse seria sugestivo de que a facilitação se daria em processos sensoriais.

Não foi observado qualquer aumento do efeito facilitador do estímulo auditivo com a complexidade perceptiva. Este resultado poderia ser em conseqüência de uma insuficiência da variação da complexidade perceptiva para promover o aumento do efeito facilitador.

No segundo experimento, a alteração encontrada na detectabilidade e no critério ressaltaram a capacidade do estímulo auditivo em promover mudanças na discriminabilidade. Este resultado está de acordo com aqueles de Lippert, Logothetis e Kayser (2007). Estes verificaram que um som melhora o desempenho em uma tarefa de detecção visual aumentando a percepção da luminância. Em complemento, Pestilli, Viera e Carrasco (2007) descreveram que atenção melhora o desempenho de uma atividade visual por aumentar a sensibilidade ao contraste e por aumentar as respostas neurais para os estímulos atendidos enquanto diminui as respostas neurais para os estímulos não atendidos.

Smith e Ratcliff (2009) descrevem que, sob algumas condições, a atenção afeta a sensibilidade de deteç̧ão e o tempo de reação de maneira equivalente, sob outras condições ela afeta o tempo de reação, mas não a sensibilidade de detecção. Tarefas de tempo de reação caracterizam um contexto de elevado número de variáveis, de modo que a atenção terá seu efeito facilitador afetado sobre a detectabilidade. Defendem, portanto, a teoria de detecção de sinal como método mais adequado para a análise do efeito da atenção sobre a detectabilidade. 
Correlacionando os resultados encontrados nos dois experimentos desta pesquisa com as descrições de Smith e Ratcliff (2009) pode-se supor que no Experimento 1 a atenção não estivesse nas condições ideais para proporcionar seu efeito facilitador sobre a detectabilidade, ainda que o tenha feito para o tempo de reação. Enquanto que no experimento 2, o método psicofísico utilizado privilegiou a manifestação do efeito atencional sobre a detectabilidade, de modo que foi possível encontrar o efeito de aumento da detectabilidade na presença do estímulo precedente.

A representação gráfica apresentada anteriormente na figura 2 descreve a possibilidade esquemática dos resultados esperados de acordo com a proposta de Sternberg. De acordo com método de fatores aditivos esperava-se encontrar uma representação gráfica como descrito na situação "B" , com a evidencia de influência sensorial sobre o processo facilitador do estímulo auditivo. Entretanto, o resultado encontrado no Experimento 1 assemelha-se ao observado na situação "A".

Se for considerado os dados obtidos nos dois experimentos, em um contexto em que a dificuldade sensorial do Experimento 1 não foi suficiente para gerar efeito esperado e que no Experimento 2 obteve-se um aumento da detectabilidade com redução do critério, a situação "A" pode representar como conjectura, além da ausência da interação dos fatores aditivos, a redução do critério. Essa possibilidade se deve à análise de que os recursos atencionais envolvidos no Experimento 1 resultaram em uma facilitação proporcional para as diferentes luminâncias. Desse modo, a participação de processos decisionais seriam menores e pouco variáveis aos estímulos, o que está de acordo com o achado de redução de critério no Experimento 2.

CORREA et al (2010) descrevem que embora vários autores defendam a idéia de que a modulação neural da orientação temporal se dá pelo processamento sensorial, as linhas de base quanto aos mecanismos que possibilitam essa facilitação permanecem indefinidos. Há uma hipótese de que a seleção de processos perceptivos seja acompanhada de regulação top-down de elementos temporais (como freqüência, por exemplo), mas não há um consenso na literatura.

Sendo assim, pode ser destacado que este trabalho reforça a contribuição sensorial na facilitação proporcionada pelo do estímulo precedente. Entretanto, 
como descrito por Correa et al (2010), ainda há o que ser investigado no que se refere aos mecanismos neurais que possibilitam essa facilitação. 


\section{CONCLUSÃO}

Os resultados obtidos nos experimentos realizados indicam que a melhora no desempenho proporcionada pelo estímulo precedente se deve à facilitação da etapa sensorial do processamento sensório-motor. 


\section{REFERÊNCIAS ${ }^{1}$}

BAIER, B.; KLEINSCHMIDT, A.; MÜLLER, N. Cross-modal processing in early visual and auditory cortices depends on expected statistical relationship of multisensory information. The Journal of Neuroscience, v. 22, n. 47, p. 12260-12265, 2006.

BERTELSON, P.; TISSEYRE, F. The time-course of preparation: Confirmatory results with visual and auditory warning signals. Acta Psychologica, v. 30, p. 145154, 1969.

CARDOSO-LEITE, P.; MAMASSIAN, P.; GOREA, A. Comparasion of perceptual and motor latencies via antecipatory and reactive response times. Attention, Perception \& Psychophysics, n. 71, v. 1, p. 82-94, 2009.

CIARAMITARO, V. M.; BURACAS, G. T.; BOYNTON, G. M. Spatial and cross-modal attention alter responses to unattended sensory information in early visual and auditory human cortex. Jounal of Neurophysiological, v. 98, p. 2399-2413, 2007.

CORREA, À.; LUPIÁÑEZ, J.; TUDELA, P. Attentional preparation based on temporal expectancy modulates processing at the perceptual level. Psychonomic Bulletin \& Review, v. 12, n. 2, p. 328-334, 2005.

CORREA, A.; LUPIÁÑEZ, J.; TUDELA, P. The attentional mechanism of temporal orienting: determinants and attributes. Experimental Brain Research, v. 169, n. 1, p. 58-68, 2006.

CORREA, A.; SANABRIA, D.; SPENCE, C.; TUDELA, P.; LUPIÁÑEZ, J. Selective temporal attention enhances the temporal resolution of visual perception: Evidence from a temporal order judgment task. Brain research, p. 202-205, 2006

CORREA, A.; CAPPUCCI, P.; NOBRE, A. C.; LUPIÁÑEZ, J. The two sides of temporal orienting. Facilitating perceptual selection, disrupting response selection. Experimental Psychology, v. 57, n. 2, p.142-148, 2010.

1 De acordo com:

ASSOCIAÇÃO BRASILEIRA DE NORMAS TÉCNICAS. NBR 6023: Informação e documentação: referências: elaboração. Rio de Janeiro, 2002. 
COULL, J. T.; FRITH, C. D.; BUCHEL, C.; NOBRE, A. C. Orienting attention in time: behavioural and neuroanatomical distinction between exogenous and endogenous shifts. Neuropsychologia, v. 38, p. 808-819, 2000.

COULL, J. T.; NOBRE, A. C. Where and when to pay attention: the neural systems for directing attention to spatial locations and to time intervals as revealed by both PET and fMRI. Journal of Neuroscience, v. 18, n. 18, p. 7426-7435, 1998.

DAVIS, R.; GREEN, F. A. Intersensory differences in the effect of warning signals on reaction time. Acta Psychologica, v. 30, p. 155-167, 1969.

DEL FAVA, F.; RIBEIRO-DO-VALLE, L. E. Relative contribuition of expectancy and immediate arousal to the facilitatory effect of an auditory acessory stimulus. Brazilian Journal Medical Biological Research, v. 37, p. 1161-1174, 2004.

DOETSCH, G. S. Patterns in the brain: neuronal population coding in the somatosensory system. Physiology \& Behavior, v. 69, p. 187-201, 2000.

FERNANDEZ-DUQUE, D.; POSNER, M. I. Relating the mechanisms of orienting and alerting. Neuropsychologia, v. 35, p. 477-486, 1997.

GAZZANIGA, M. S.; HEATHERTON, T. F. Ciência psicológica: mente, cérebro e comportamento. Porto Alegre: Artmed, 2005. 624 p.

GESCHEIDER, G. A. Psychophysics: the fundamentals. 3rd ed. New Jersey: Lawrence Erlbaum Associates, 1997. 435 p.

HACKLEY, S. A.; VALLE-INCLÁN, F. Which stages of processing are speeded by a warning signal? Biological Psychology, v. 64, p. 27-45, out 2003.

HENDERSON, L.; DITTRICH, W. H. Preparing to react in the absence of uncertainty: I. New perspectives on simple reaction time. British Journal of Psychology, v. 89, p. 531-554, 1998.

HOMMEL, B. No prevalence of right-left over top-bottom spatial codes. Perception \& Psychophysics, v. 58, n. 1, p. 102-110, 1996.

KEUSS, P. J. G. Reaction time to the second of two shortly spaced auditory signals both varying in intensity. Acta Psychologica, v. 36, p. 226-238, 1972. 
KLAPP, S. T. Motor response programming during simple and choice reaction time: the role of practice. Journal of Experimental Psychology: Human Perception and Performance, v. 21, n. 5, p. 1015-1027, 1995.

LANGE, K.; RÖDER, B. Orienting attention to points in time improves stimulus processing both within and across modalities. Journal of Cognitive Neuroscience, v. 18, n. 5, p. 715-729, 2006.

LANGE, K.; RÖSLER, F.; RÖDER, B. Early processing stages are modulated when auditory stimuli are presented at an attended moment in time: An event-related potential study.. Psychophysiology, v. 40, p. 806-817, 2003.

LANSING, R. W.; SCHWARTZ, E.; LINDSLEY, D. B. Reaction time and EEG activation under alerted and nonalerted conditions. Journal of Experimental Psychology, v. 58, p. 1-7, 1959.

LETOURNEAU, J. E.; DENIS, R.; LONDORF, D. Influence of auditory or visual warning on visual reaction time with variations of subjects' alertness. Perceptual and Motor Skills, v. 62, p. 667-674, 1986.

LEUTHOLD, H. Programming of expected and unexpected movements: effects on the onset of the lateralized readiness potential. Acta Psychologica, v. 114, p. 83100, 2003.

LIPPERT, M.; LOGOTHESIS, N. K.; KAYSER, C. Improvement of visual contrast detection by a simultaneous sound. Brain Research, v. 1173, p. 102-109, 2007.

LOS, S. A.; KNOL, D. L.; BOERS, R. M. The foreperiod effect revisited: conditioning as a basis for nonspecific preparation. Acta Psychologica, v. 106, p. 121-145, 2001.

MACMILLAN, N. A.; CREELMAN, C. D. Detection theory: a user's guide. 2nd ed. London: Lawrence Erlbaum Associates, 2005. 492 p.

MAGEN, H.; COHEN, A. Action-based and vision-based selection of input: two sources of control. Psychological Research, v. 66, p. 247-259, 2002. 
MAUK, M. D.; BUONOMANO, D. V. The neural basis of temporal processing. Annual Review of Neuroscience, v. 27, p. 307-340, 2004.

MILLER, J.; ANBAR, R. Expectancy and frequency effects on perceptual and motor systems in choice reaction time. Memory and Cognition, v. 9, p. 631-641, 1981.

MILLER, J.; FRANZ, V.; ULRICH, R. Effects of auditory stimulus intensity on response force in simple, go/no-go, and choice RT tasks. Perception and Psychophysics, v. 61, p. 107-119, 1999.

MINIUSSI, C.; WILDING, E. L.; COULL, J. T.; NOBRE, A. C. Orienting attention in time-modulation of brain potentials. Brain, v. 122, p. 1507-1518, 1999.

MULLER-GETHMANN, H.; ULRICH, R.; RINKENAUER, G. Locus of effect of temporal preparation: evidence from the lateralized readness potential. Psychophysiology, v. 40, p. 597-611, 2003.

NIEMI, P.; NÄÄTÄNEN, R. Foreperiod and simple reaction time. Psychological Bulletin, v. 89, p. 133-162, 1981.

NOBRE, A. C.; CORREA, A.; COULL, J. T. The hazards of time. Current Opinion in Neurobiology, v. 17, p. 465-470, 2007.

OLDFIELD, R. C. The assessment and analysis of handedness: the Edinburgh inventory. Neuropsychologia, v. 9, p. 97-113, 1971.

PALMER, S. E. Vision Science - photons to phenomenology. England: MIT Press, 1999.

PESTILLI, F.; VIERA, G.; CARRASCO, M. How do attention and adaptation affect contrast sensitivity? Journal of Vision, v. 7, n. 9, p. 1-12, 2007.

PESTILLI, F.; LING, S.; CARRASCO, M. A population-coding modelo $f$ attention's influence on contrast response: estimating neural effects from psychophysical data. Vision Research, 2008.

PINHEIRO, G. B. Envolvimento de mecanismos sensoriais e motores na facilitação do tempo de reação produzida por um estímulo precedente. 2006. 90 
f. Dissertação (Mestrado em Ciências) - Instituto de Ciências Biomédicas, Universidade de São Paulo, São Paulo, 2006.

ROBINSON, C.; SLOUTSKY, V. Visual processing speed: effects of auditory input on visual processing. Developmental Science, v. 10, n. 6, p. 734-740, 2007.

ROLKE, B.; HOFMANN, P. Temporal uncertainty degrades perceptual processing. Psychonomic Bulletin \& Review, v. 14, n. 3, p. 522-526, 2007.

SANABRIA, D.; LUPIÁÑEZ, J.; SPENCE, C. Auditory motion affects visual motion perception in a speed discrimination task. Experimental Brain Research, v. 178, p. 415-421, 2007.

SMITH, P. L.; RATCLIFF, R. An integrated theory of attention and decision making in visual signal detection. Psychological Review, v. 116, n. 2, p. 283-317, 2009.

SANDERS, L. D.; ASTHEIMER, L. B. Temporally selective attention modulates early perceptual processing: Event-related potential evidence. Perception \& Psychophysics, v. 70, n. 4, p. 732-742, 2008.

SIMOLA, J.; STENACKA, L.; VANNI, S. Topography of attention in the primary visual cortex. European Journal of Neuroscience, v. 29, p. 188-196, 2009.

SQUELLA, S. A. F.; RIBEIRO-DO-VALLE, L. E. Priming effects of a peripheral visual stimulus in simple and go/no-go tasks. Brazilian Journal of Medical and Biological Research, v. 36, p. 247-261, 2003.

STELMACH, G. E. Information-processing framework for understanding human motor behavior. In: KELSO, J. A. S. (Ed). Human motor behavior: an introduction. New Jersey: Lawrence Erlbaum, 1982. p. 63-91.

STERNBERG, S. The discovery of processing stages: extensions of Donders' method. Acta Psychologica, v. 30, p. 276-315, 1969.

STOFFELS, E. J. On stage robustness and response selection routes: further evidence. Acta Psychologica, v. 91, p. 67-88, 1996.

ULRICH, R.; MATTES, S. Does immediate arousal enhance response force in simple reaction time? The Quarterly Journal of Experimental Psychology, v. 49A, p. $972-$ 990, 1996. 
WERNER, L. A.; PARRISH, H. K.; HOLMER, N. M. Effects of temporal uncertainty and temporal expectancy on infantes'auditory sensitivity. Journal of Acoustical Society of America, v. 125, n. 2, p. 1040-1049, 2009.

WRIGHT, D. B.; HORRY, R.; SKAGERBERG, E. M. Functions for traditional and multilevel approaches to signal detection theory. Behavior Research Methods, v. 2, n. 41, p. 257-267, 2009. 


\section{ANEXOS}

\section{ANEXO A}

\section{TEORIA DE DETECÇÃO DE SINAL}

A teoria de detecção de sinal é um método que possibilita o estudo da relação entre estímulos físicos e as respostas dos sistemas perceptivos, abordagem psicofísica para mensurar o desempenho.

Apesar de não se caracterizar uma metodologia inovadora, o método ainda é considerado na literatura como sendo atual e detém credibilidade como instrumento de pesquisa. O recente trabalho de Wright e Skagerberg (2009), por exemplo, compara a abordagem tradicional da teoria de detecção de sinal, onde se calcula a acurácia da resposta de cada indivíduo e depois se realiza análise estatística do grupo, com a abordagem multinivel da teoria de detecção de sinal, que se diferencia pela necessidade da predição da resposta por parte de cada participante. Em suas discussões, eles ressaltam a eficácia do método tradicional da teoria de detecção de sinal como um método seguro para análise psicofísica.

Em geral, tem sido utilizada por médicos e pesquisadores fisiologistas para situações que requeiram discriminação, como medir a habilidade do diagnóstico do médico em distinguir exames de Raio-X que apresentam tumores daqueles que apresentam tecidos normais (GESCHEIDER, 1997; MACMILLAN e CREELMAN, 2005).

Para Gazzaniga e Heatherton (2005), de acordo com a teoria de detecção de sinal, há quatro variáveis críticas para a detecção de um estímulo: sinal, resposta, ruído e viés da resposta. As duas últimas variáveis refletem a ambigüidade da situação sinal-detecção. $O$ conceito de ruído foi estabelecido para explicar o efeito variável que um estímulo pode ter sobre os sistemas sensoriais. Os estímulos estão sempre competindo com um fundo mutável de outros eventos perceptivos e psicológicos, de modo que sua saliência nem sempre será a mesma. $O$ viés da resposta varia de acordo com quantas evidências são necessárias para 0 observador antes que ele dê a resposta. Em algumas situações, o observador terá um forte viés contra dar uma resposta e necessitará de muitas evidências quanto à 
presença do sinal. Em outras situações, o mesmo observador pode necessitar de apenas uma pequena quantidade de evidências.

$\mathrm{Na}$ teoria de detecção de sinal um julgamento é um evento em que o sinal pode, ou não, estar presente. Se o sinal estiver presente e o observado detectá-lo, o resultado será um acerto. $O$ fracasso em detectar um sinal verdadeiro se chama erro. Se o observador "detectar" erroneamente um estímulo que não estava lá, o resultado é um alarme falso. E se o estímulo não for apresentado e o observador negar tê-lo visto o resultado é uma rejeição correta. Os teóricos da detecção de sinal ressaltam que a sensibilidade do observador ao estímulo só pode ser calculada comparando-se o índice de acertos com o índice de alarmes falsos, para que assim possa ser corrigido qualquer viés que o observador poderia trazer para a situação de testagem (GAZZANIGA e HEATHERTON, 2005)

Quando se verifica a habilidade de se distinguir estímulos, essa distinção pode ser mais ou menos precisa. A medida de sensibilidade pode ser representada em alta ou baixa. Uma alta sensibilidade refere-se a uma boa habilidade em discriminar. Uma baixa sensibilidade refere-se a uma habilidade pior. Macmillan e Creelman (2005) descreveram essa medida de sensibilidade por meio de uma tarefa de "sim-não". Eles descreveram, por exemplo, o desempenho dos participantes em uma tarefa de reconhecimento de face. Nesta tarefa são apresentados aos participantes uma série de slides com face das pessoas e eles são instruídos a lembrar-se delas. Após um certo período o reconhecimento é testado. Aos mesmos participantes são apresentados uma outra série de slides com algumas das mesmas fotos da série anterior. Uma condição que representa boa memória ocorre quando os participantes reconhecem as faces antigas e não reconhecem as faces novas. $O$ experimento pretende justamente medir a habilidade em distinguir as duas séries de slides. Os participantes respondiam "sim" para as faces em que julgavam terem visto anteriormente e diziam "não" para àquelas que julgavam não terem visto anteriormente.

Por convenção, utiliza-se preferencialmente uma linguagem militar para descrever o experimento "sim-não". O reconhecimento correto para a face velha seria denominado de hit (acerto). A falha no reconhecimento seria miss (erro). Reconhecer uma face errada (face nova) como certa (dizer que é face antiga) caracteriza um reconhecimento errado e é descrito como false alarm (alarme falso). 
E afirmar corretamente que não é uma face velha corresponde a uma correct rejection (rejeição correta). Somente duas dessas quatro condições fornecem informações independentes sobre o desempenho dos participantes, por exemplo o número de acertos e alarmes falsos. A razão de hit $(\mathrm{H})$ é a proporção de tentativas com faces antigas ao qual o participante respondeu "sim" (número de acertos dividido pelo número total de possíveis acertos). O termo sensibilidade é usado como sinônimo para razão de hit. E a razão de false alarm $(F)$ é a proporção de tentativas com faces novas similares, porém respondidas incorretamente (número de julgamentos incorretos divididos pelo número total de julgamentos corretos possíveis). A razão de hit e de false alarm pode ser descrita como condições de probabilidade.

Ainda de acordo com a descrição de Macmillan e Creelman (2005), o participante com perfeita sensibilidade deveria ter um $\mathrm{H}$ de 1 e um $\mathrm{F}$ de 0 (zero). $\mathrm{O}$ participante completamente insensível deve ser incapaz de distinguir dois estímulos entre todos. A probabilidade de dizer "sim", para estes observadores, pode não depender dos estímulos apresentados, portanto a razão de hit e de false alarm pode ser a mesma.

A detectabilidade pode aumentar quando $\circ \mathrm{H}$ aumenta ou $\mathrm{F}$ diminui. $\mathrm{A}$ diferença entre $\mathrm{H}$ e $\mathrm{F}(\mathrm{H}-\mathrm{F})$ representa o aumento da sensibilidade pelo aumento de $\mathrm{H}$ e redução de $\mathrm{F}$. A medida é chamada d' ("dee-prime") e é definida nos termos de $z$, a função inversa da distribuição normal:

$$
d^{\prime}=z(H)-z(F) \text {. }
$$

Quando os observadores conseguem discriminar, a razão de hit é maior do que 0.5 e a razão de false alarm é menor do que 0.5 , e o d' pode ser obtido adicionando o valor absoluto do correspondente $z$ score. Quando os observadores não conseguem discriminar, pode ser observado o cenário onde $H=F$ e d' $=0$. Muitos experimentadores consideram a condição $H=0.99$ e $F=0.01$, d' $=4.65$, como o teto efetivo. Por outro lado, o aumento da sensibilidade, aumenta o número de hits, e aumenta o d', ao ponto que a acurácia perfeita pode ser alcançada com $\mathrm{H}$ $=1, F=0$ e d' infinito.

O cálculo do d' em tarefa de discriminação de acordo com a teoria de detecção de sinal é uma boa medida de sensibilidade devido ao fato de que uma boa medida de sensibilidade deve ser invariável quando a sensibilidade ou outros 
fatores mudam. Pela teoria de detecção, os participantes possuem a sensibilidade fixada quando solicitados a discriminar um par específico de estímulos.

A validade da teoria de deteç̧ão de sinal claramente depende da descrição do d' ao representar as mudanças ocorridas em $\mathrm{H}$ e $\mathrm{F}$ quando o critério é manipulado. De acordo com o modelo da teoria de detecção de sinal (TDS) o d', como já mencionado, representa a diferença entre a razão transformada de hit e false alarm. Além disso, fornece uma boa descrição da relação entre $\mathrm{H}$ e $\mathrm{F}$ quando $\mathrm{o}$ critério varia.

Por interpretação, o critério é a tendência de se responder considerando fatores como preferência para uma determinada resposta, de modo a estar relacionado com o processo decisório. O processo decisório requer detecção, análise e escolha da resposta, envolve várias etapas do processamento sensóriomotor, incluindo aquelas que ocorrem nas áreas associativas.

O d' corresponde a um aspecto fixado da decisão do observador e é representado pela diferença entre $\mathrm{H}$ e F. A medida do critério deve também refletir na característica apropriada da representação perceptiva. $O$ indicador do critério, por sua vez, deve depender da soma dos termos envolvendo $\mathrm{H}$ e F. No exemplo de reconhecimento de face, as estatísticas do critério podem refletir o grau de dominância de respostas "sim" e o grau de preferências por respostas "não". Um critério positivo é representado pela tendência em dizer "não", enquanto que um critério negativo corresponde à tendência de dizer "sim". Essa aparente falta de lógica pode ser melhor compreendida quando se representa a medida para calcular o critério:

$$
c=-1 / 2[z(H)+z(F)]
$$

Se o critério aumenta, o $\mathrm{H}$ e $\mathrm{F}$ irão diminuir. Enquanto que se o critério diminui, $\mathrm{H}$ e $\mathrm{F}$ aumentam.

Muitos hits e poucos false alarms indicam uma maior discriminabilidade e, portanto, um maior envolvimento dos mecanismos sensoriais ao invés dos mecanismos envolvidos na tomada de decisão. Esse aumento da influência sensorial é representado pelo aumento do distanciamento das curvas e deslocamento do critério. Uma vez que o pico entre duas curvas representa a detectabilidade, quanto maior o distanciamento entre os picos, maior a detectabilidade ou sensibilidade (Figura 17). 

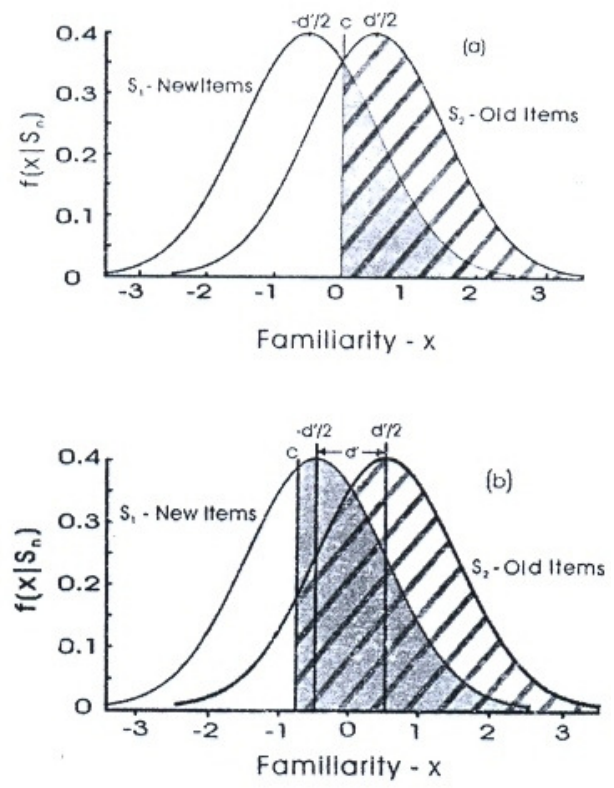

Figura 17: Representação de um exemplo de tarefa "sim-não" para reconhecimento de face. a) Os participantes respondiam "sim" para as faces em que julgavam terem visto anteriormente e diziam "não" para àquelas que julgavam não terem visto anteriormente. As curvas $S 1$ e S2 representam, respectivamente, o reconhecimento de faces novas e faces antigas e delimitam o critério. b) A distância entre os picos das duas curvas representa a detectabilidade. 